\title{
INTERFACIAL PROCESSES IN MINERAL/WATER SYSTEMS
}

\author{
D. W. FUERSTENAU
}

Department of Materials Science and Engineering, University of California, Berkeley, California, U.S.A.

\begin{abstract}
Factors that control the selective adsorption of both inorganic and organic ions at mineral/water interfaces are reviewed and summarized. In particular, the role of the electrical double layer in the adsorption of surface-active materials on oxides in aqueous media is stressed. The importance of interfacial processes to mineral chemistry is illustrated through the application of specific adsorption phenomena to the understanding of the physical chemistry of flotation systems.
\end{abstract}

\section{INTRODUCTION}

MINERAL/WATER interfacial phenomena are of great significance in many fields ranging from geochemical processes in nature, through the behaviour of soils, to the processing of mineral raw materials. What is important in such systems is that solutes in the aqueous phase adsorb at mineral/water interfaces, sometimes under almost universal conditions and sometimes only under selective conditions. Selective adsorption of inorganic ions may account for the concentrations of metals in certain mineral deposits ${ }^{1}$ and in sediments and concretions of the sea floor ${ }^{2}$. Selective adsorption of organic ions permits the separation of minerals from each other by the process of flotation. In general, the role of adsorption has not been given a great deal of attention by the geochemist, whereas significant progress has been made by soil scientists and flotation engineers through application of the physics and chemistry of surfaces to their problems.

The importance of interfacial processes to mineral chemistry can perhaps be illustrated through discussion of the application of surface chemistry research to the understanding of the flotation process. Flotation is that process wherein.finely ground minerals are made hydrophobic so that they can be attached to air bubbles and separated in a froth from the rest of the slurry. Most flotation separations are based on the selective adsorption of amphipathic organic reagents (called collectors) at mineral/water interfaces. Although flotation is concerned to a large extent with the specific adsorption of organic electrolytes, many of the principles that will be discussed are also relevant to mineral/water interfacial behaviour in other fields.

Separation of minerals by flotation developed as an art about sixty years ago $^{3}$, but the need for separating increasingly complex mixtures of minerals 


\section{W. FUERSTENAU}

has necessitated scientific research that is directed towards understanding the basic physical chemistry of this important process. Perhaps a summary of the different methods that can be utilized for the flotation separation of iron ores will illustrate the complexity of the chemistry of flotation systems. Five different procedures have been developed for the flotation of haematite $\left(\mathrm{Fe}_{2} \mathrm{O}_{3}\right)$ from quartz $\left(\mathrm{SiO}_{2}\right)$ or vice versa :

(1) Flotation of haematite using a sulphonate as the collector at $\mathrm{pH} 2$ to 4.

(2) Flotation of haematite with a fatty acid as the collector at a $\mathrm{pH}$ of 6 to 8 .

(3) Flotation of quartz with an amine as collector at a $\mathrm{pH}$ of 6 to 7.

(4) Flotation of quartz activated with calcium ions at $\mathrm{pH} 11$ to 12 , using a soap as the collector together with starch to depress the haematite.

(5) Flotation of haematite with an amine as collector at $\mathrm{pH} 1.5$ in the presence of hydrochloric acid or sulphuric acid.

What is the physical chemical basis for selective adsorption in these systems? To answer such questions and to develop new flotation procedures for making appropriate mineral separations, extensive research in applied surface chemistry is required.

One of the earliest research tools used for such flotation investigations was the determination of factors that affect contact angles, a technique used with great success by Wark and his co-workers in Australia ${ }^{4}$. Since most flotation separations are based on the selective adsorption of collectors at mineral water interfaces, direct measurement of the amount of the reagent adsorbed permits physical chemical analysis of the adsorption phenomena as it relates to wettability. Gaudin ${ }^{5}$ and his co-workers determined adsorption isotherms of a number of collectors on a variety of minerals, leading the way in this important approach to flotation chemistry. Another significant step in delineating the physical chemistry of flotation systems was the bringing of the concepts of the electrical double layer into widespread use in the interpretation of flotation phenomena ${ }^{6-10}$. Figure 1 shows how the results of all these methods of experimentation can be correlated with the flotation of quartz using dodecylammonium acetate (DAA) as collector ${ }^{11}$. This figure illustrates how measurements that reflect conditions at the solid/liquid interface (adsorption density and zeta potential) can be correlated directly with surface phenomena that reflect complex conditions at solid/liquid/gas interfaces (contact angle and flotation-behaviour). The significance of the shape of these curves will be brought out later.

Significant progress has been made during the past three decades in delineating the physical chemistry of flotation systems through the utilization of a number of experimental techniques, such as those used in obtaining the results presented in Figure 1 . If we are to continue to increase our basic knowledge of the chemistry of the flotation process, continued research using a combination of experimental and theoretical techniques will be required, and most importantly this research should be carried out on materials that have been well characterized. Further, these materials should have properties that have relevance to the behaviour of minerals in flotation systems, important examples being oxides and sulphides.

Perhaps two examples of materials that have unsuitable properties for making collector adsorption and flotation investigations might be cited. As is well known, the favourite research material of colloid chemists is silver 


\section{INTERFACIAL PROCESSES IN MINERAL/WATER SYSTEMS}

iodide, the study of which has done so much for us in understanding the role of the double layer in coagulation phenomena. However, use of this material for flotation studies has limited value in helping us understand flotation systems because silver halides are inherently hydrophobic ${ }^{10,12,13}$. Similarly, one of the materials that has been widely used by surface chemists and electrochemists for research in the electrical double layer is mercury. Even

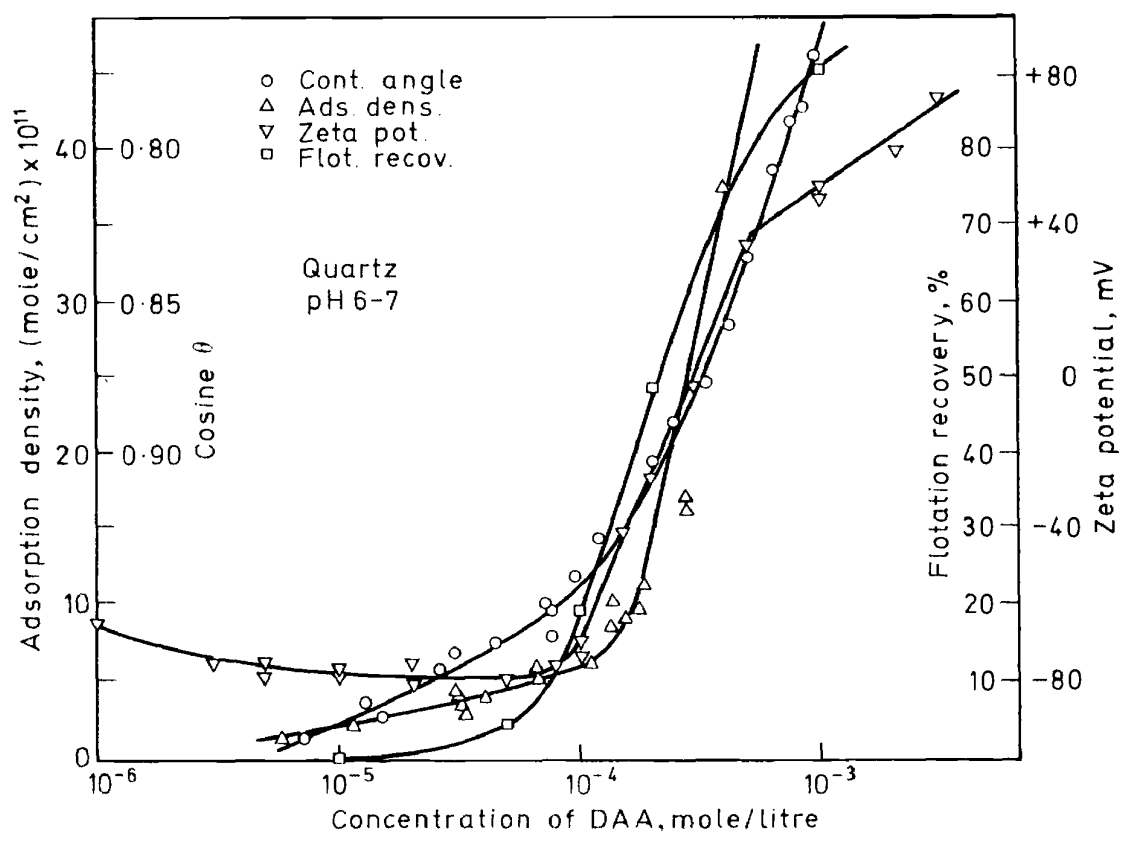

Figure 1. Correlation among contact angle, adsorption density, flotation response, and zeta potential for quartz as a function of dodecylammonium acetate (DAA) concentration at $\mathrm{pH}$ 6 to 7

with its excellent properties for study of adsorption and double layer phenomena mercury is unsuited for collector adsorption studies because of its hydrophobic properties ${ }^{14}$ which result in strong hydrophobic bonding of a collector to the surface of mercury ${ }^{15}$.

As indicated by the diversity of methods through which haematite or quartz can be made selectively hydrophobic, the conditions for adsorption of surfactants at mineral/water interfaces depend upon a variety of factors. In the following sections the present state of our knowledge of the adsorption of surface-active agents in flotation systems will be developed, using mainly oxide minerals as examples, to show how surface chemistry research can be utilized to explain the complicated chemistry of mineral/water flotation systems. Some of the problems that remain to be solved will be pointed out. 


\section{THE ELECTRICAL DOUBLE LAYER ON MINERALS}

Since adsorption phenomena at mineral/water interfaces are usually controlled by the electrical double layer, we must be concerned with factors responsible for the charge on the mineral surface and with the behaviour of ions that adsorb as counter ions to maintain electroneutrality.

In the layer silicate minerals such as the clays and the micas, because of substitution of $\mathrm{Al}^{3+}$ for $\mathrm{Si}^{4+}$ in the silica tetrahedra or $\mathrm{Mg}^{2+}$ for $\mathrm{Al}^{3+}$ in the octahedral layer of the crystal lattice, the surfaces of these crystal faces carry a negative charge that is independent of solution conditions. In the salt-type minerals such as barium sulphate, calcium fluoride, silver sulphide etc, the surface charge arises from the preference of one of the lattice ions for the solid in relation to the aqueous phase. Equilibrium is attained when the electrochemical potential, $\bar{\mu}=\mu+z F \phi$, of these ions is constant throughout the system. Those particular ions which are free to pass between both phases and therefore establish the electrical double layer are called potentialdetermining ions.

For the oxide minerals, hydrogen and hydroxyl ions have long been considered to be potential-determining ${ }^{16,17}$. Today there still remains a difference in opinion as to how $\mathrm{pH}$ controls the surface charge on oxides. Since oxide minerals form hydroxylated surfaces when in contact with water vapour, a hydroxylated surface should be expected when the solid is in equilibrium with an aqueous solution. Adsorption-dissociation of $\mathrm{H}^{+}$from the surface hydroxyls can account for the surface charge on the oxide ${ }^{18,19}$ :

$$
\begin{aligned}
& \mathrm{MOH}_{(\text {surf })} \rightleftharpoons \mathrm{MO}_{\text {(surf) }}^{-}+\mathrm{H}_{\text {(aq) }}^{+} \\
& \mathrm{MOH}_{(\text {surf })}+\mathrm{H}_{\text {(aq) }}^{+} \rightleftharpoons \mathrm{MOH}_{2 \text { (surf) }}^{+}
\end{aligned}
$$

Parks and deBruyn ${ }^{20,21}$ have postulated a different mechanism for the charging of oxide surfaces, involving partial dissolution of the oxide and formation of hydroxyl complexes in solution, followed by adsorption of these complexes:

$$
\begin{aligned}
\mathrm{M}_{2} \mathrm{O}_{3 \text { (solid) }} & +3 \mathrm{H}_{2} \mathrm{O} \rightleftharpoons 2 \mathrm{M}(\mathrm{OH})_{3(\mathrm{aq})} \\
\mathrm{M}(\mathrm{OH})_{3 \text { (aq) }} & \rightleftharpoons \mathrm{M}(\mathrm{OH})_{m \text { (aq) }}^{3-m}+(3-m) \mathrm{OH}_{(\mathrm{aq})}^{-} \\
\mathrm{M}(\mathrm{OH})_{m \text { (aq) }}^{3-m} & \rightleftharpoons \mathrm{M}(\mathrm{OH})_{m(\text { surf })}^{3-m}
\end{aligned}
$$

The formation of a surface charge by either of these mechanisms, or even by direct adsorption of $\mathrm{H}^{+}$and $\mathrm{OH}^{-}$, would result in a change in the $\mathrm{pH}$ of the solution. In any case, the surface charge $\sigma_{s}$, on an oxide mineral can be expressed as

$$
\sigma_{s}=F\left(\Gamma_{\mathrm{H}^{+}}-\Gamma_{\mathrm{OH}^{-}}\right)
$$

where the adsorption density. $\left(\Gamma_{\mathrm{H}^{+}}+\Gamma_{\mathrm{OH}^{-}}\right)$mole per $\mathrm{cm}^{2}$, can be measured by acid-base titration of a suspension of the oxide mineral in water ${ }^{20} . F$ is the Faraday constant. Similarly, the surface charge on a mineral such as silver sulphide can be determined by titration with soluble silver or sulphide salts, provided the surface area of the solid is known.

The single most important parameter that describes the electrical double 


\section{INTERFACIAL PROCESSES IN MINERAL/WATER SYSTEMS}

layer of a mineral in water is the point of zero surface charge (PZC). The PZC is expressed as the condition in the aqueous solution at which $\sigma_{s}$ is zero and this is determined by a particular value of the activity of the potentialdetermining ion $\left(a_{\mathrm{pzc}}^{+}\right.$or $\left.a_{\mathrm{pzc}}^{-}\right)$. Assuming that potential differences due to dipoles, etc., remain constant, the surface potential $\psi_{0}$ is considered to be zero at the PZC. The value of the surface potential at any activity of potentialdetermining electrolyte, $a^{+}$, is given by

$$
\psi_{0}=\left(R T / z^{+} F\right) \ln \left(a^{+} / a_{\mathrm{pzc}}^{+}\right)
$$

where $R$ is the gas constant, $T$ the absolute temperature, and $z^{+}$the valence of the potential-determining cation.

To the mineral chemist, the adsorption of counter ions that occurs to maintain electroneutrality in the system is of importance. In contrast to the situation in which the potential-determining ions are special for each system, any ions present in the solution can function as the counter ions. As has been well established, the counter ions occur in a diffuse layer that extends from the interface out into the solution. The closest distance of approach of counter ions to the surface is one (hydrated) ionic radius away, shown as the distance $\delta$ in Figure 2. Depending on the ionic strength of the solution, there is a

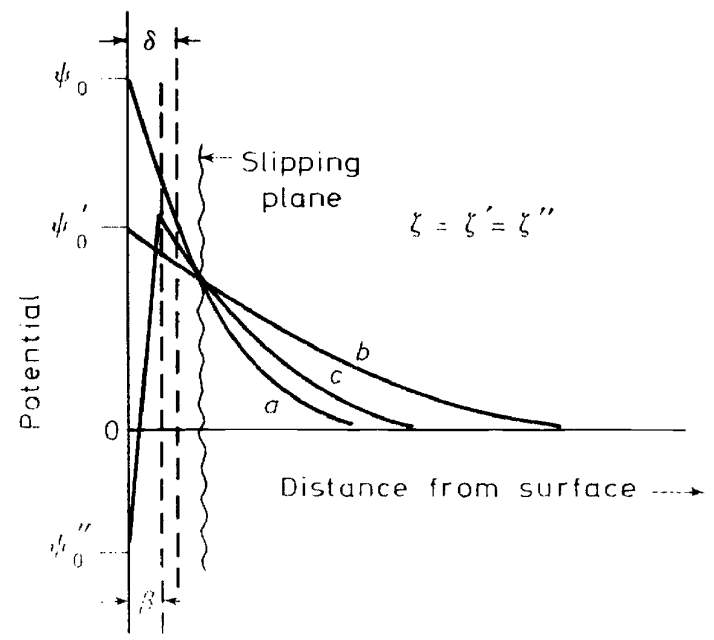

Figure 2. The variation of potential through the double layer for $(a)$ a higher concentration of potential-determining ion, (b) a lower concentration of potential-determining ion, and (c) in the presence of a specifically adsorbed counter ion with the potential-determining ion being below the point of zero charge. Note that the zeta potential in all three instances could be identical. In each case, $\psi_{\delta}$ is the potential at the plane $\delta$; and for case $e ; \psi_{\beta}$ is the potential at the plane $\beta$.

considerable drop in potential between the solid surface and the plane $\delta$ (Figure 2), this potential drop being $\psi_{0}-\psi_{\delta}$.

If counter ions are adsorbed only by electrostatic attraction, they are called indifferent electrolytes. On the other hand, some ions exhibit surface activity 


\section{W. FUERSTENAU}

in addition to electrostatic attraction because of such phenomena as covalent bond formation, hydrophobic bonding, hydrogen bonding, solvation effects, etc. Because of their surface activity, such counter ions may be able to reverse the sign of $\psi_{\delta}$ because the charge of such ions adsorbed exceeds the surface charge. Colloid chemists often refer to this ${ }^{22}$ phenomenon as the 'reversal of charge'; however, this is not charge reversal but reversal of $\psi_{\delta}$ since the surface charge $\sigma_{s}$ or surface potential $\psi_{0}$ retains its sign and nearly its same magnitude. Grahame ${ }^{23}$ suggested that hydrated indifferent ions lie in a plane that is farther from the surface than dehydrated specifically adsorbed ions (see Figure 2), calling the two planes the outer and inner Helmholtz planes, respectively. In the case of large specifically adsorbed organic ions, the inner Helmholtz plane may actually lie outside the outer Helmholtz plane. Since the outer Helmholtz plane is quite commonly referred to as the Stern plane, perhaps a less confusing way to discuss these adsorption planes might be to refer to the outer Helmholtz plane as the Stern plane and the inner Helmholtz plane as the Grahame plane, giving credit to the two $\operatorname{men}^{23,24}$ who first postulated the existence of each of these planes in the context of modern double layer theory.

\section{Electrokinetics}

Electrokinetic phenomena, which involve the interrelation between mechanical and electrical effects at a moving interface, have found widespread use in colloid and surface chemistry. The two electrokinetic effects that have been most widely used are electrophoresis and streaming potential; however, expression of electrokinetic results in terms of zeta potentials has at times been rather widely criticized ${ }^{25}$. Yet, if the significance of the electrokinetic potential is kept in mind, such measurements do prove to be exceedingly useful in applied surface chemistry research. Since the zeta potential is the potential at the slipping plane when liquid is forced to move relative to the solid, only ions in the diffuse layer outside the slipping plane are those that are involved in the electrokinetic process. All sorts of charge compositions on the surface and in the Grahame and Stern planes can give the same zeta potential (see Figure 2). Thus, while knowledge of the zeta potential at some single condition may be of limited value, determination of the change in zeta potentials as solution conditions are varied may be extremely useful. From these changes, modes of adsorption of various kinds of ions can be ascertained if one makes the useful assumption that the slipping plane and the Stern plane coincide ${ }^{26}$. This approximation seems permissible because the potential difference between the plane $\delta$ and the slipping plane is small compared to the total potential difference across the double layer. In the case of micelles, Stigter ${ }^{27}$ recently showed that the slipping plane might occur within $1 \AA$ of the polar heads of the ions constituting the micelle. Lyklema and Overbeek ${ }^{28}$ have suggested a gradual transition between the mobile and immobile parts of the double layer in such systems. However, it is of interest to note that the electrokinetic potential has been found to be independent of Reynolds number, ranging from laminar to turbulent flow conditions $^{29}$. Finally, the condition under which there may be no ambiguity is when $\psi_{\delta}=0$, for then $\zeta$ must be zero ${ }^{30}$. 


\section{SURFACE CHARGE ON OXIDE MINERALS}

As already stated, the most significant parameter controlling the behaviour of solids in an aqueous environment is its PZC. However, in systems where chemical interaction occurs between adsorbing species and the solid, the chemical nature of the metallic cations constituting the lattice would also become important.

\section{Experimental evaluation of the PZC of minerals}

Experimentally the PZC of a mineral can be evaluated by a number of methods including titration, electrokinetics, maximum coagulation, the suspension effect, change in the concentration of potential-determining ions in solution upon the addition of dry powder, etc. Figure 3 presents the results of a series of experiments designed to evaluate the PZC of alumina by four of
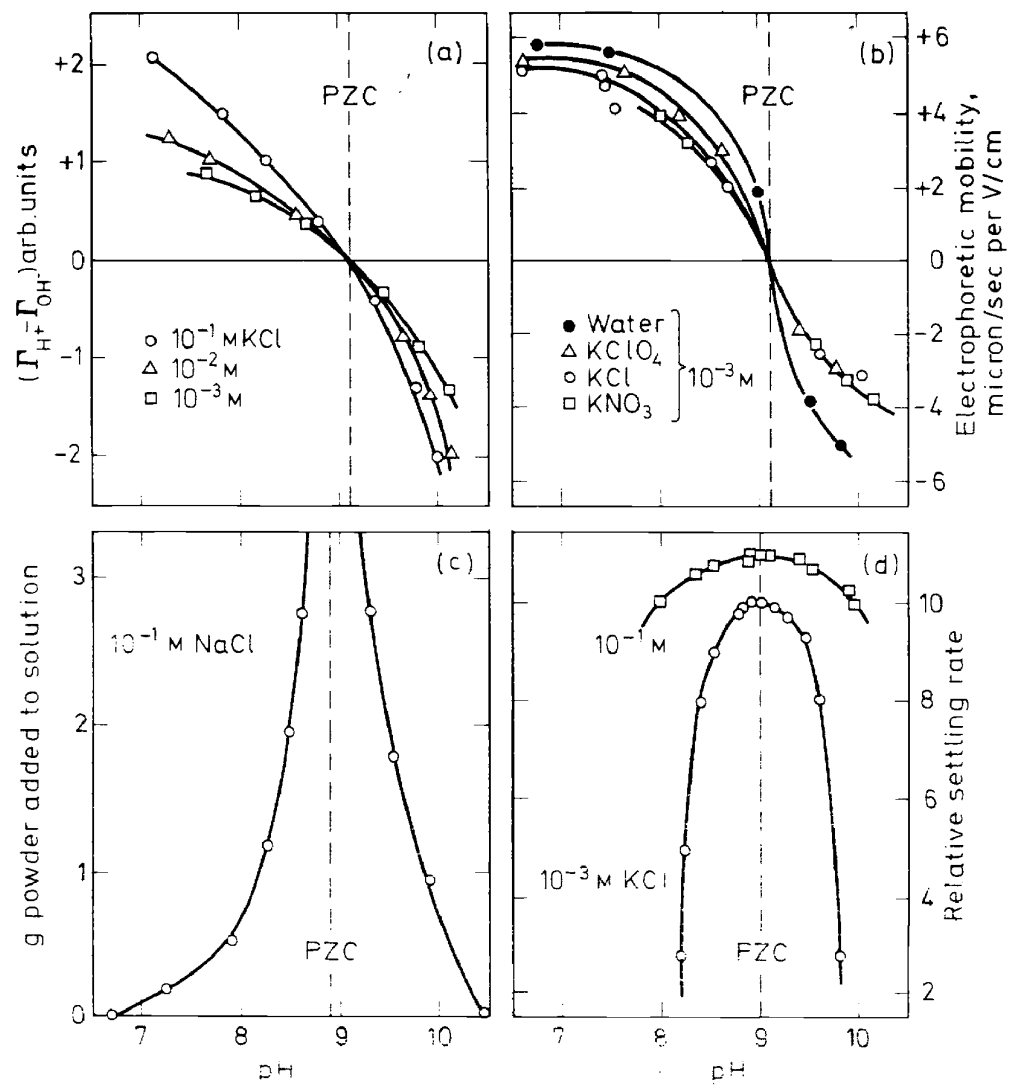

Figure 3. Determination of the point of zero charge of alumin (Linde- $A$ ) by meanss of $(a)$ titration, (b) electrophoresis, (c) the addition of dry powder to solutions, and (d) maximum coagulation ${ }^{1:}$. these methods, using potassium or sodium salts as the supporting electrolyte. As can be seen, the PZC of this alumina sample (Linde-A) occurs at $\mathrm{pH}$ $9 \cdot 0 \pm 0 \cdot 1$. For this given material, the agreement between the methods is 


\section{W. FUERSTENAU}

quite striking. On the other hand, results that are obtained by various workers on different samples of materials often differ widely.

Table 1 presents the results of the research of a number of investigators on the evaluation of the PZC of quartz (or silica). As can be seen, silica has been

Table 1. Experimental measurement of PZC of quartz (silica)

\begin{tabular}{|c|c|c|c|}
\hline Materials & $P Z C$ & Method & Reference \\
\hline Quartz (Brazil) & $\mathrm{pH} 3.6$ & Titration & Ahmed $^{32}$ \\
\hline Quartz (Brazil) & pH 3.7 & Stream. pot. & Gaudin and Fuerstenau ${ }^{7}$ \\
\hline Synth. silica & $\mathrm{pH} 3 \cdot 7$ & Titration & Bolt $^{34}$ \\
\hline Synth. silica & pH 3 & Titration & Tadros and Lyklema ${ }^{35}$ \\
\hline Ouartz (New Mex.) & pH 3.7 & Electrophoresis & Deju and Bhappu ${ }^{33}$ \\
\hline Quartz (New Mex.) & $\mathrm{pH} 1 \cdot 8$ & Electrophoresis & Deju and Bhappu ${ }^{33}$ \\
\hline Quartz (Brazil) & $\sim \mathrm{pH} 3$ & Titration & $\mathrm{Li}$ and deBruyn ${ }^{36}$ \\
\hline Quartz (Brazil) & $\sim \mathrm{pH} 1.3 \dagger$ & Stream. pot. & Li and deBruyn ${ }^{36}$ \\
\hline Quartz (Montana) & pH 2.5 & Electrophoresis & Iwasaki et al. $^{37}$ \\
\hline Quartz crystals & $\sim \mathrm{pH} 1.5 \dagger$ & Stream. pot. & Cases $^{38}$ \\
\hline Quartz crystals & $<\mathrm{pH} 3 t$ & Electrophoresis & O'Connor and Buchanan 39 \\
\hline Quartz, milky & $\mathrm{pH} 2 \cdot 8$ & Stream. pot. & Healy ${ }^{40}$ \\
\hline Quartz crystals & $\ddagger$ & Stream. pot. & Parreira and Schulman ${ }^{41}$ \\
\hline
\end{tabular}

$†$ By extrapolation. $\ddagger$ No reversal obtained, but zero charge at $\mathrm{pH} 2$.

found by some researchers to reverse its surface charge at $\mathrm{pH}$ values as high as 3.7 whereas others have found that the PZC of quartz may lie between $\mathrm{pH}$ 1 and 2 . Some even report ${ }^{41,64}$ that they were unable to reverse the sign of the surface charge of quartz as the $\mathrm{pH}$ was lowered. By electrophoresis, Deju and Bhappu ${ }^{33}$ found that untreated New Mexico quartz exhibited a PZC at pH 37 whereas leaching with concentrated hydrochloric acid reduced its PZC to a pH around 1.4 to 1.8 , depending on the leach time. Similarly, they observed that the PZC of Brazil quartz occurred at $\mathrm{pH} 1.5$ after it had been leached for eight hours in concentrated hydrochloric acid.

Table 2 presents a summary of the results that have been obtained by various investigators who measured the $\mathrm{PZC}$ of haematite. In general, synthetic haematite has been found to have a PZC between $\mathrm{pH} 8$ and 9, whereas the PZC of natural haematite is usually considerably lower. Perhaps

Table 2. Experimental measurement of PZC of haematite

\begin{tabular}{|c|c|c|c|}
\hline Materials & $P Z C$ & Method & Reference \\
\hline Synth. haematite & $\mathrm{pH} 9 \cdot 0$ & Titration & Quirk et al. ${ }^{42}$ \\
\hline Synth. haematite & $\mathrm{pH} 8.4$ & Titration & Parks and deBruyn ${ }^{20}$ \\
\hline Synth. haematite & $\mathrm{pH} 8 \cdot 3$ & Electrophoresis & Troelstra and Kruyt ${ }^{43}$ \\
\hline Haematite (Quebec) & $\mathrm{pH} 5.4$ & Titration & Ahmed and Maksimov 44 \\
\hline Haematite (Quebec) & $\mathrm{pH} 8 \cdot 7$ & Titration & Smith and Salman ${ }^{45}$ \\
\hline Haematite (Brazil) & pH 5.4 & Stream pot. & Joy et al. ${ }^{46}$ \\
\hline Haematite (Brazil) & pH $5 \cdot 7$ & Titration & Joy et al. ${ }^{46}$ \\
\hline Haematite (Minn.) & pH 6.7 & Electrophoresis & Iwasaki et al. ${ }^{47}$ \\
\hline Haematite & pH 6.7 & Electrophoresis & Johansen and Buchanan ${ }^{48}$ \\
\hline
\end{tabular}


the most perplexing findings are those of Joy and Watson ${ }^{49}$, who fractionated a natural haematite from Itabira into various species:

(1) 'orange fines' with a particle size of about $200 \AA$,

(2) 'red fines' with a particle size of 5 to 10 microns,

(3) 'black species' (specular haematite) constituting the bulk of the sample and ranging in size up to about $1 \mathrm{~mm}$.

The PZC of the orange fines occurred at $\mathrm{pH} \mathrm{4}$, that of the red fines at $\mathrm{pH} 8$, and that of the black species ranged from $\mathrm{pH} 3$ to 6.7 , depending on the particle size and the leaching pretreatment. Such wide range in surface properties of particles produced from the same ore sample clearly indicates the necessity for characterization of materials used in mineral/water surface chemistry research. Joy and Watson did attempt to characterize their materials but were unable to find any real correlations.

Parks ${ }^{50}$ has summarized the results obtained on other oxides; they too exhibit widely differing PZCs.

A few researchers have begun to attempt to delineate factors that might be responsible for variations in the behaviour of minerals in water: Parks has considered the effects of impurities ${ }^{50}$; Healy, Herring and Fuerstenau have considered crystal structure ${ }^{51}$; Lyklema $^{52}$ has examined the role of micropores; O'Connor, Johansen and Buchanan ${ }^{53}$ have looked at surface dehydration; Pravdic and Sotman ${ }^{54}$ have considered the effect of stoichiometry.

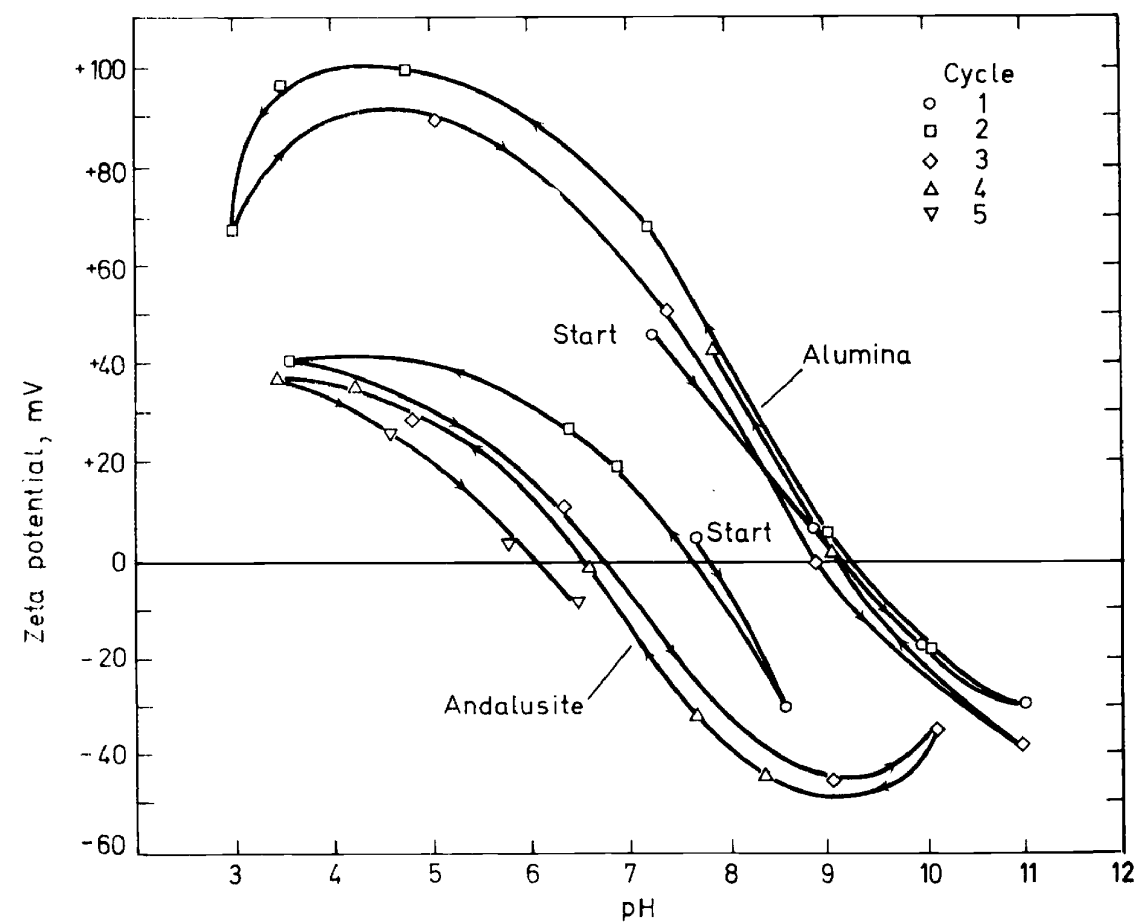

Figure 4. Hysteresis in the point of zero charge of corundum $\left(\mathrm{Al}_{2} \mathrm{O}_{3}\right)$ and andalusite $\left(\mathrm{Al}_{2} \mathrm{O}_{3} \cdot \mathrm{SiO}_{2}\right)$ through acid-base cycling in a streaming potential apparatus ${ }^{50.51}$. 


\section{W. FUERSTENAU}

With oxide minerals, if one cycles between acidic and basic $\mathrm{pHs}$, hysteresis in the PZC is generally found to be small, and essentially insignificant ${ }^{50}$. However, hysteresis has been observed to be quite large in aluminosilicate minerals ${ }^{57}$. Figure 4 shows that the PZC of alumina ${ }^{56}$ shifts very little with acid-base cycling in a streaming potential cell; whereas in the case of andalusite $\left(\mathrm{Al}_{2} \mathrm{O}_{3} \cdot \mathrm{SiO}_{2}\right)$, the PZC shifts towards a more acidic $\mathrm{pH}$ with every cycle ${ }^{57}$. If the PZC is considered to be determined by the fraction of the AlOH and the $\mathrm{SiOH}$ sites in the surface, selective leaching of $\mathrm{AlOH}$ from the surface



Figure 5. The adsorption density of potential-determining ions on ferric oxide as a function of $\mathrm{pH}$ and ionic strength using potassium nitrate as the indifferent electrolyte $\mathrm{e}^{20}$.

would cause the PZC to shift towards a lower $\mathrm{pH}$. Such leaching of the aluminosilicates has been found to occur ${ }^{57}$. It should be noted that Joy, Manser, Lloyd and Watson ${ }^{58}$, in a study of feldspars, found that all surface aluminium ions were removed by a simple leach at $\mathrm{pH} 3$. Thus, interpretation of surface phenomena with the complex oxide minerals may well be complicated indeed. 


\section{INTERFACIAL PROCESSES IN MINERAL/WATER SYSTEMS}

A few attempts have been made to predict the PZCs of oxides ${ }^{21,50,55}$, but such predictions are of little significance as long as we still are unable to explain the kinds of wide deviations shown in Tables 1 and 2.

\section{The surface charge on oxides}

By titrating a suspension of finely divided oxide in water in the presence of an indifferent electrolyte, the surface charge can be evaluated. Figure 5 presents the results of Parks and deBruyn on the acid-base titration of ferric oxide $^{20}$. The intersection of the curves shows that the PZC of this material occurs at $\mathrm{pH} 8 \cdot 4$. As has also been found by others, e.g. by Atkinson, Posner and Quirk $^{42}$, the adsorption isotherms are linear with $\mathrm{pH}$ at high ionic strengths and can be represented by an equation of the form

$$
\left(\Gamma_{\mathrm{H}^{+}}-\Gamma_{\mathrm{OH}^{-}}\right)=-k\left(\mathrm{pH}-\mathrm{pH}_{\mathrm{pzc}}\right)
$$

where $\mathrm{pH}_{\mathrm{pzc}}$ is the $\mathrm{pH}$ of the solution at the $\mathrm{PZC}$ of ferric oxide.

Since the surface potential also varies directly with $\mathrm{pH}$, according to

$$
\psi_{0}=2 \cdot 3(R T / F)\left(\mathrm{pH}_{\mathrm{pzc}}-\mathrm{pH}\right)
$$

then the capacity of the double layer (and more specifically the capacity of the Stern layer) must remain constant in oxide--water systems. More careful experimentation will be required for this observation to be confirmed.

\section{SPECIFIC ADSORPTION OF INORGANIC IONS}

In many scientific and technological fields, the specific adsorption of inorganic ions has been found to be exceedingly important. Several methods exist for experimentally detecting specific adsorption and those that are quite commonly used involve (1) the reversal of the electrokinetic potential and (2) the shift in the PZC by titration.

In the absence of specific adsorption, the standard free energy of adsorption of an ion of valence $z$ into the Stern plane will be given by

$$
\Delta \bar{G}_{\mathrm{ads}}^{0}=z F \psi_{\delta}
$$

if the only interaction is due to coulombic forces. In the case of oxides, the alkali cations appear to be surface-inactive. Such anions as nitrate have been shown ${ }^{60}$ to be surface-inactive on $\mathrm{SnO}_{2}, \mathrm{TiO}_{2}, \mathrm{Al}_{2} \mathrm{O}_{3}$ and $\mathrm{Fe}_{2} \mathrm{O}_{3}$. Chloride ions are not surface active on $\mathrm{Al}_{2} \mathrm{O}_{3}$ but are specifically adsorbed ${ }^{60}$ on $\mathrm{Fe}_{2} \mathrm{O}_{3}$.

When an ion exhibits surface activity, the standard free energy of adsorption has additional terms

$$
\Delta \bar{G}_{\mathrm{ads}}^{0}=z F \psi_{\delta}+\Delta G_{\mathrm{spec}}^{0}
$$

where $\Delta G_{\text {spec }}^{0}$ represents the specific interaction terms. In terms of the model of the electrical double layer, it is possible to estimate $\Delta G_{\mathrm{spec}}^{0}$ at the reversal of the electrokinetic potential (i.e. when $\psi_{\delta}=0$ ) by considering the double layer to be a molecular condenser under these conditions ${ }^{61}$.

Figure 6 illustrates the specific adsorption of inorganic electrolytes on alumina. As can be seen, sulphate ions reverse the sign of $\zeta$ when the surface of alumina is positively charged but they lose their surface activity when the 


\section{W. FUERSTENAU}

surface is negatively charged. Thiosulphate ions behave identically with sulphate ions ${ }^{31}$. On the other hand, barium ions are specifically adsorbed on negatively charged alumina but not on the positively charged solid. Other examples of the reversal of $\zeta$ by alkaline earth cations are barium ions on

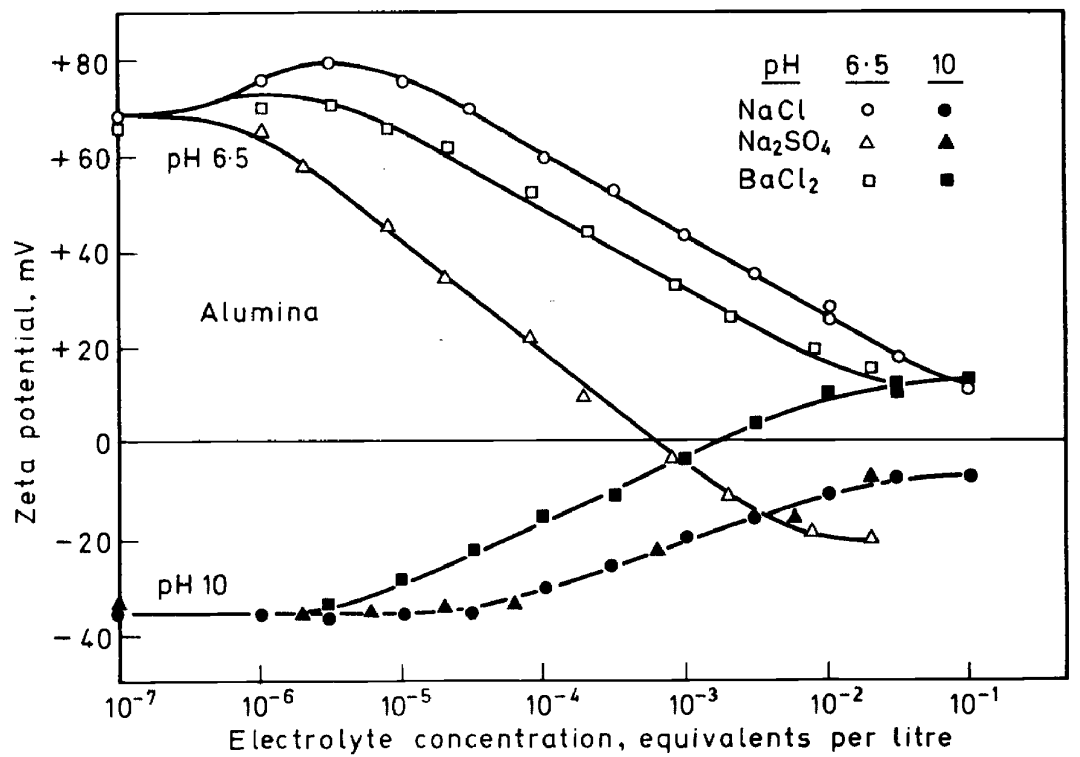

Figure 6. The zeta potential of alumina at $\mathrm{pH} 6.5$ and $\mathrm{pH} 10$ as a function of $[\mathrm{NaCl}],\left[\mathrm{Na}_{2} \mathrm{SO}_{4}\right]$ and $\left[\mathrm{BaCl}_{2}\right]^{31}$.

quartz $\mathrm{z}^{33}$ at $\mathrm{pH} 7$ and calcium ions on rutile $\mathrm{e}^{59}$ at a $\mathrm{pH}$ ranging from 7 to 11. With $\mathrm{Ba}^{2+}$ on quartz at $\mathrm{pH} 6.5$, the zeta potential was found to reverse at $4 \times 10^{-2}$ equivalents of $\mathrm{Ba}^{2+}$ per litre, whereas upon adding $\mathrm{Al}^{3+}$ to water initially at $\mathrm{pH} 6.5$, the zeta potential of quartz was found to reverse at a concentration ${ }^{33}$ of $2 \times 10^{-6}$ equivalents per litre. In the latter case, $\mathrm{Al}^{3+}$ was beginning to hydrolyse; the surface activity of hydrolysed aluminium species must be 20000 -fold that of barium ions. During the last ten years there has been an extensive amount of research directed towards understanding the role of hydrolysed metal ions in coagulation processes ${ }^{22}$, and this work has clearly demonstrated that hydrolysed cations exhibit exceptionally strong surface affinity.

In considering the role of hydrolysis in the adsorption of metal cations, let us first briefly review the behaviour of such ions in aqueous solution. About forty years ago, Brönsted postulated that multivalent metal ions participate in a series of consecutive proton transfers. In the case of ferric ion, this can be represented by the following sequence:

$$
\begin{aligned}
\mathrm{Fe}\left(\mathrm{H}_{2} \mathrm{O}\right)_{6}^{3+} & \rightleftharpoons\left[\mathrm{Fe}\left(\mathrm{H}_{2} \mathrm{O}\right)_{5} \mathrm{OH}\right]^{2+}+\mathrm{H}^{+} \\
\rightleftharpoons\left[\mathrm{Fe}\left(\mathrm{H}_{2} \mathrm{O}\right)_{4}(\mathrm{OH})_{2}\right]^{+}+2 \mathrm{H}^{+} & \\
& \rightleftharpoons\left[\mathrm{Fe}\left(\mathrm{H}_{2} \mathrm{O}\right)_{3}(\mathrm{OH})_{3}\right]+3 \mathrm{H}^{+} \\
& \quad 146
\end{aligned}
$$




$$
\rightleftharpoons\left[\mathrm{Fe}\left(\mathrm{H}_{2} \mathrm{O}\right)_{2}(\mathrm{OH})_{4}\right]^{-}+4 \mathrm{H}^{+}
$$

Also, the hydrolysed species may dimerize (and polymerize) by a condensation process:

$$
2\left[\mathrm{Fe}\left(\mathrm{H}_{2} \mathrm{O}\right)_{5} \mathrm{OH}\right]^{2+} \rightleftharpoons\left[\left(\mathrm{H}_{2} \mathrm{O}\right)_{4} \mathrm{Fe}_{\mathrm{HO}}^{\prime}{ }^{\prime} \mathrm{Fe}\left(\mathrm{H}_{2} \mathrm{O}\right)_{4}\right]^{4+}+2 \mathrm{H}_{2} \mathrm{O}
$$

These various polymeric ions may well be the surface-active species.

Now, if we are concerned with an oxide mineral, increasing the $\mathrm{pH}$ will have a somewhat more complicated effect on adsorption because of three phenomena. Upon increasing the $\mathrm{pH}$, based on what we have discussed thus far,

(1) the surface charge and surface potential become more negative (or less positive),

(2) hydrolysis of the metal cations begins to occur,

(3) precipitation of the metal hydroxide eventually prevails.

On the other hand, $\mathrm{pH}$ will not affect the surface charge of a solid such as silver iodide. Abramson, Jaycock and Ottewill ${ }^{62}$ have clearly shown that hydrolysed lanthanum cations adsorb more strongly on silver iodide than do the unhydrolysed $\mathrm{La}^{3+}$ ions. The electrophoretic studies which they carried out at the same time demonstrate that increased adsorption occurs

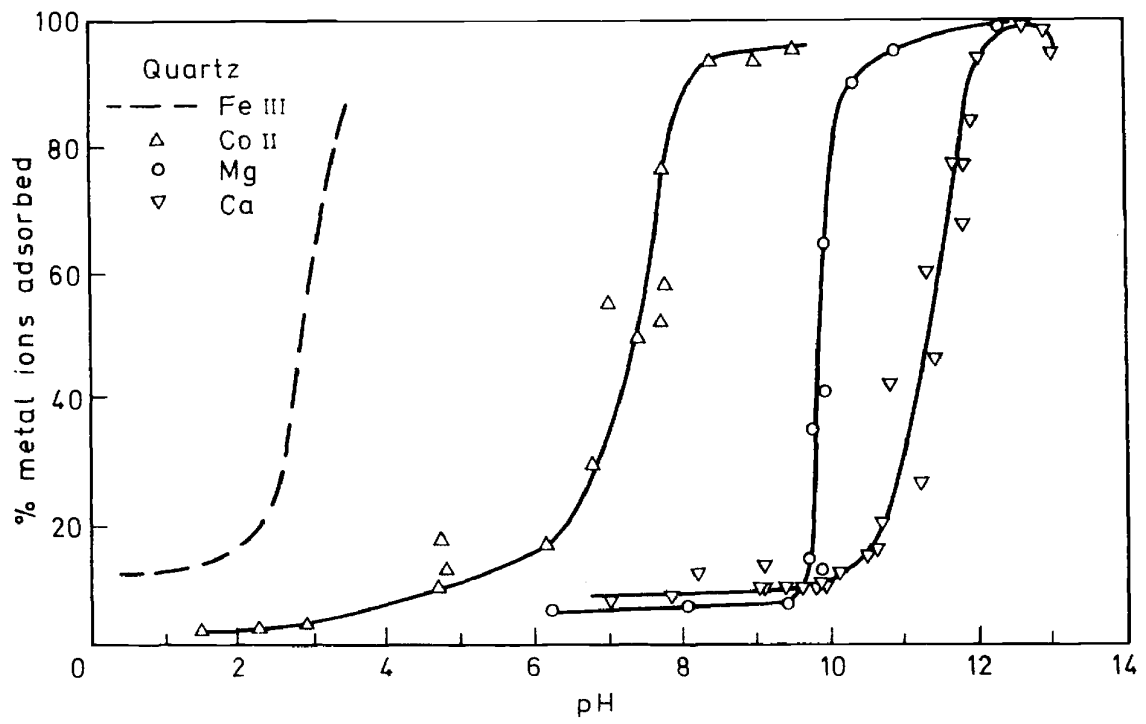

Figure 7. The percentage of added metal cations adsorbed on quartz as a function of $\mathrm{pH}$. Fe $\mathrm{mI}$ and $\mathrm{Co}$ Il concentrations initially were $1 \times 10^{-4} \mathrm{M}^{63,64} ; \mathrm{Mg}$ and $\mathrm{Ca}$ concentrations initially were $4 \times 10^{-3} \mathrm{M}$ and $3 \times 10^{-3} \mathrm{M}$, respectively ${ }^{65}$.

under the same $\mathrm{pH}$ conditions that bring about the reversal of the zeta potential of silver iodide.

Figure 7 presents the combined results of studies by a number of investigators on the adsorption of various metal ions on quartz. In this figure, the 
D. W. FUERSTENAU

adsorption of $\mathrm{FellI}^{63}, \mathrm{Coll}^{64}, \mathrm{Mg}^{65}$ and $\mathrm{Ca}^{65}$ are given as a function of solution $\mathrm{pH}$ and the results are presented in terms of the percentage of metal cations present that are adsorbed. On a pure oxide such as quartz, only limited data have thus far been published on the effect of $\mathrm{pH}$ on the electrokinetic behaviour in the presence of hydrolysing cations. Figure 8 presents the zeta potential of quartz as a function of $\mathrm{pH}$ in water, in $6 \times 10^{-3} \mathrm{M}$ ferric chloride, and in $4 \times 10^{-3} \mathrm{M}$ cobaltous nitrate ${ }^{66}$.

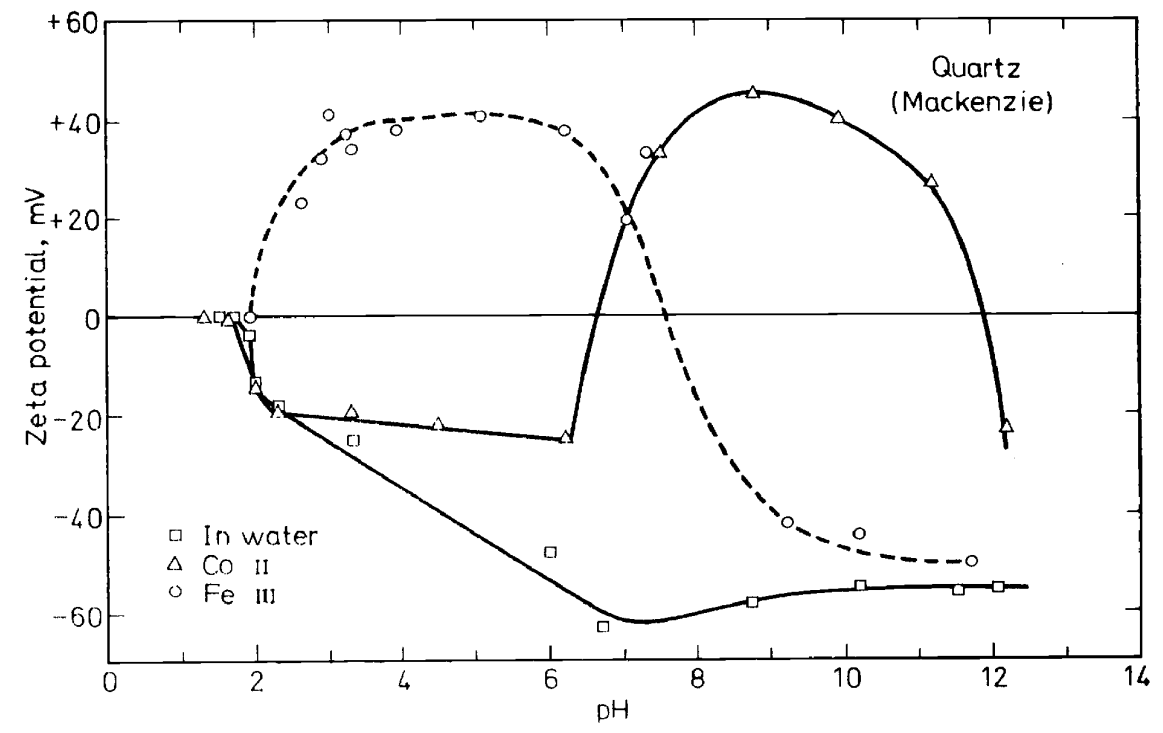

Figure 8. The zeta potential of quartz as a function of $\mathrm{pH}$ in water and in the presence of $4 \times 10^{-3}$ $\mathrm{M} \mathrm{Co}\left(\mathrm{NO}_{3}\right)_{2}$ and $6 \times 10^{-3} \mathrm{M} \mathrm{FeCl}_{3}{ }^{66}$.

These limited data show that metal cations become exceptionally surface active when they begin to hydrolyse and reverse $\zeta$. As the $\mathrm{pH}$ is increased further, the metal hydroxide colloids begin to form and these coat the surface of the silica particles by a heterocoagulation process. The second reversal of the zeta potential at the higher $\mathrm{pHs}$ results from the charge reversal of the hydroxide colloid itself ${ }^{64,66}$; as the hydroxide colloid becomes negatively charged, it redisperses and the measured zeta potential approaches that of the bare surface. Figure 8 indicates that unhydrolysed $\mathrm{Co}^{2+}$ might exhibit limited surface-activity because of the deviation of the zeta potential curve from that observed in water.

At this stage, the mechanism by which inorganic ions acquire their surface activity is essentially not understood at all. Some have suggested that chemisorption of such ions as $\mathrm{Ba}^{2+}$ on silica results from the formation of a barium silicate bond ${ }^{7,67}$. However, the limited results thus far obtained seem to point to a somewhat general phenomenon that any multivalent inorganic ion can reverse the zeta potential of an oxide when the surface is charged oppositely to the cation. It has been suggested that this surface activity may merely result from the multivalent ion parking on a single site at the surface, 


\section{INTERFACIAL PROCESSES IN MINERAL/WATER SYSTEMS}

the distance between the adsorbed multivalent ions being sufficiently large that electrostatic repulsion between adsorbed ions at the point of zeta potential reversal would not be overwhelming. With hydrolysed cations, surface activity must result from a combination of coulombic and specific adsorption effects. The very great surface activity of hydrolysed metal ions has often been suggested by numerous researchers to result from hydrogen bonding with surface hydroxyl and surface oxygen sites. However, hydrolysed cations specifically adsorb on AgI equally well and a hydrogen bonding mechanism would not seem to be applicable in this case. Perhaps the ordered water structure at the solid/water interface will be found to be important in these phenomena.

The future, no doubt, will see continued research on adsorption of both hydrolysed and nonhydrolysed inorganic ions because of their extreme importance in such phenomena as the geochemistry of mineral deposits (including the sea floor manganese nodules), coagulation of suspended solids, activation in flotation, etc.

\section{SPECIFIC ADSORPTION OF ORGANIC IONS}

The amphipathic nature of organic ions has a marked effect on their adsorption. The nature of the polar head on the molecule or ion controls whether there is any chemical interaction with the mineral, whereas the structure of the hydrocarbon chain determines the extent of its interaction with the aqueous media.

The standard free energy of adsorption of an organic ion at a mineral/water interface is given by

$$
\Delta \bar{G}_{\mathrm{ads}}^{0}=\Delta G_{\text {elect }}^{0}+\Delta G_{\text {hydroph }}^{0}+\Delta G_{\text {chem }}^{0}+\ldots
$$

where $\Delta G_{\text {elect }}^{0}=z F \psi_{\delta}, \Delta G_{\text {hydroph }}^{0}$ represents the interaction due to association of hydrocarbon chains of adsorbed ions at the surface, $\Delta G_{\text {chem }}^{0}$ represents the free energy due to the formation of covalent bonds with the surface, etc.

At this point, it may be of value to discuss terminology concerned with the mechanism of adsorption of organic ions at solid/water interfaces. If the ions are adsorbed only with such forces as electrostatic attraction and hydrophobic bonding (van der Waals interaction between the hydrocarbon chains), the process should be termed physical adsorption. If the surfactant forms covalent bonds with metal atoms in the surface, then the process should be termed chemisorption. Examples of physical adsorption in mineral/water systems include alkylammonium ions on quartz ${ }^{68}$ and alkyl sulphonates on alumina $^{69}$. In this context, Ter-Minassian-Saraga's use of the term chemisorption for alkylammonium ions on silica is misleading ${ }^{70}$. Examples of chemisorption of surfactants are the oleate-fluorite system ${ }^{71}$ and the oleatehaematite system ${ }^{72}$. Infra-red spectroscopy has demonstrated the existence of calcium oleate bonds and ferric oleate surface bonds on these two respective minerals.

Thus far, much of the detailed research that has been carried out on surfactant adsorption at mineral/water interfaces has been concerned with the two physical adsorption systems: alkylammonium-quartz and alkyl 


\section{W. FUERSTENAU}

sulphonate-alumina. The adsorption isotherms ${ }^{68}$ and electrokinetic ${ }^{73}$. behaviour of the alkylammonium-quartz system strongly suggested that at low concentrations, the surfactant ions are adsorbed as individual counter ions but that at higher concentrations they associate through interaction of the hydrocarbon chains of those ions adsorbed in the Stern layer. This association of the adsorbed species into two-dimensional aggregates at the surface has been termed hemi-micelles ${ }^{73}$. The sharp break upwards in the adsorption isotherm shown in Figure 1 reflects hemi-micelle formation. Note that because of the higher concentration at the interface, this occurs at a bulk concentration of about $10^{-4} \mathrm{M}$ DAA, which is but one-one hundredth of the bulk critical micelle concentration for this material. Figure 1 clearly shows that a sharp reversal in the zeta potential of quartz occurs upon formation of hemi-micelles. Likewise, there is a marked change in wettability, as indicated by the contact angle and flotation behaviour.

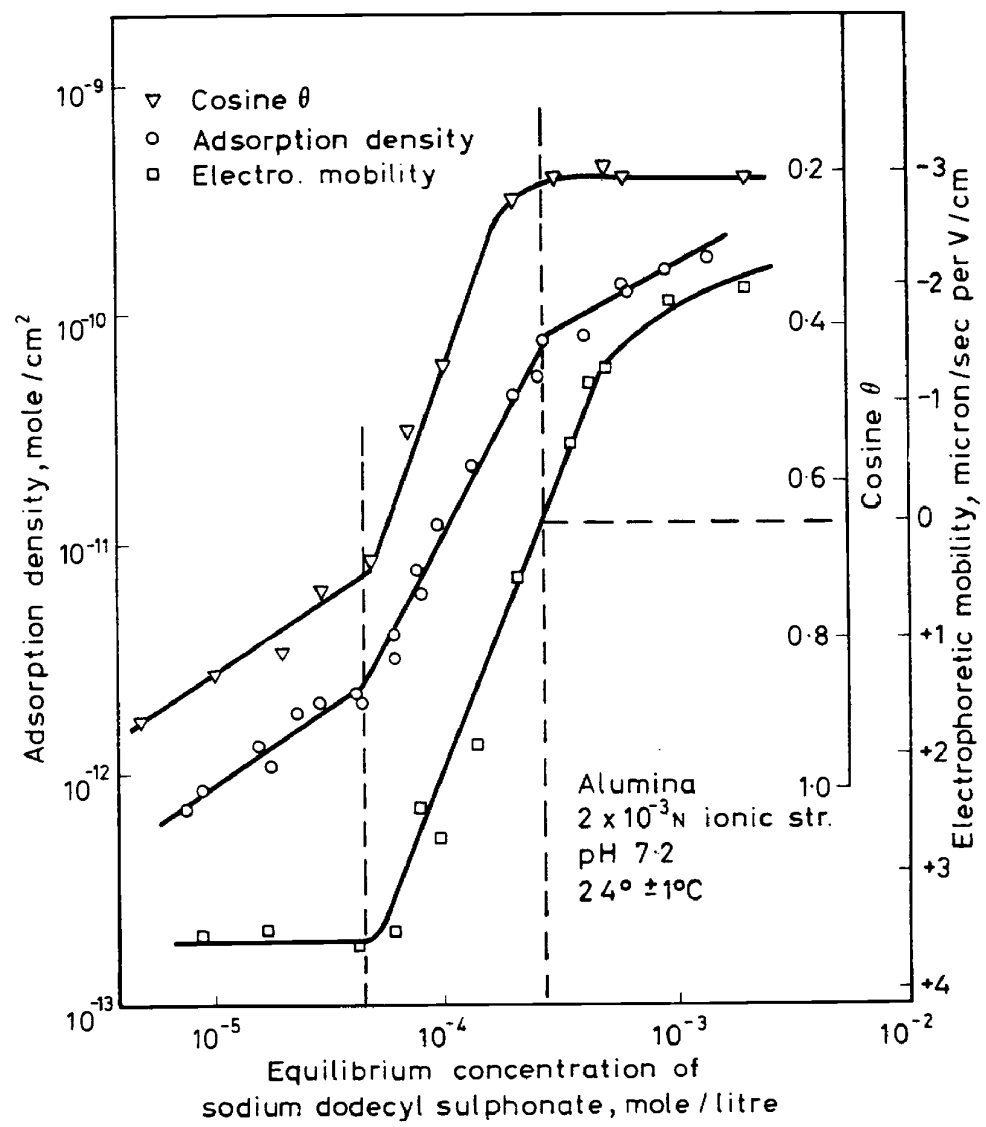

Figure 9. The adsorption density of sodium dodecyl sulphonate on (Linde-A) alumina, the electrophoretic mobility of alumina, and the contact angle on alumina as a function of the equilibrium concentration of sodium dodecyl sulphonate at pH 7.2 and ionic strength of $2 \times 10^{-} \mathrm{N}$ controlled with sodium chloride ${ }^{76}$ 


\section{INTERFACIAL PROCESSES AT MINERAL/WATER INTERFACES}

Recently adsorption in the alumina-alkyl sulphonate system has been studied in considerable detail ${ }^{69,74,75}$. Figure 9 presents the effect of the concentration of dodecyl sulphonate on the electrophoretic mobility, adsorption density and contact angle on alumina at $\mathrm{pH} 7 \cdot 2$, and at an ionic strength of $2 \times 10^{-3} \mathrm{~N}$, controlled by sodium chloride ${ }^{75}$. From Figure 9 it can be seen that these adsorption phenomena can be divided into three distinct regions. At low concentrations, adsorption of sulphonate ions occurs by exchange with chloride ions in the double layer; during the exchange, the mobility remains constant. In this region only the electrostatic adsorption potential is active. In the second region, the adsorbed ions begin to associate with adsorption increasing markedly due to the enhanced adsorption potential because $\Delta G_{\text {hydroph }}^{0}$ is active. The third region is reached when the zeta potential reverses. At concentrations higher than this, the electrostatic interaction

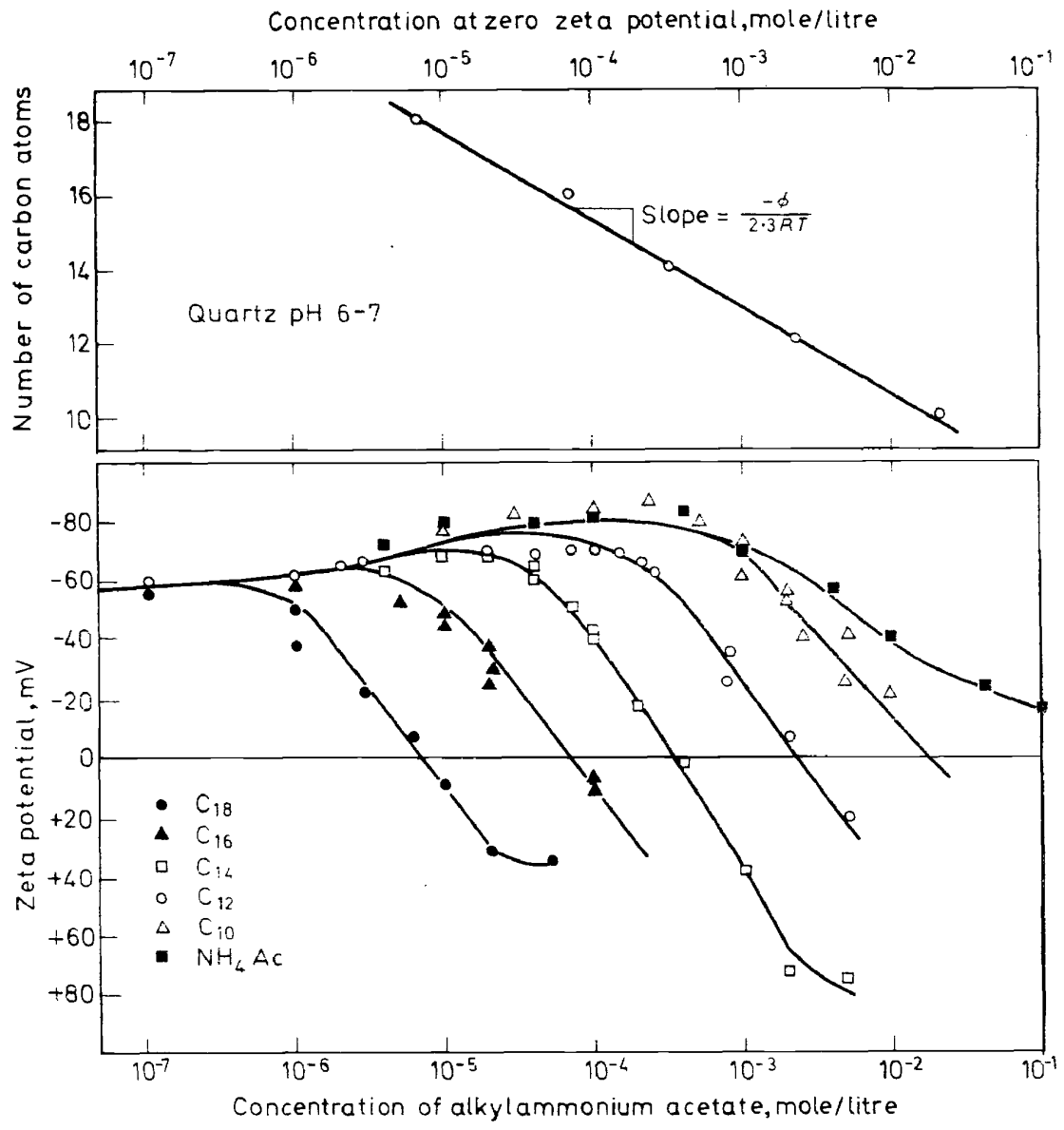

Figure 10. The effect of hydrocarbon chain length on the zeta potential of quartz at neutral pH in solutions of alkylammonium acetates; the variation of the concentration of alkylammonium acetate required reverses the sign of $\zeta$ as a function of the number of carbon atoms ${ }^{79}$. 


\section{W. FUERSTENAU}

opposes the specific adsorption effects, with the resulting decrease in the slope of the adsorption isotherm.

Somasundaran ${ }^{69}$ has clearly demonstrated that the adsorption of anionic dodecyl sulphonate ions occurs only when the alumina is positively charged and decreases sharply as the $\mathrm{pH}$ of alumina is increased towards the PZC. Iwasaki, Cooke and $\mathrm{Kim}^{76}$ showed the adsorption of dodecyl sulphate ions to occur only significantly when magnetite $\left(\mathrm{Fe}_{3} \mathrm{O}_{4}\right)$ is positively charged and conversely dodecylammonium ions adsorb when magnetite is negatively charged. A totally inexplicable finding, on the other hand, is that of Tamamushi and Tamaki $^{77}$ who measured almost identical adsorption of dodecylpyridinium bromide and sodium dodecyl sulphate on alumina; in their work, the surfactant that adsorbed most strongly was dodecylammonium chloride.

If the specific adsorption of an amine salt on quartz or a sulphonate on alumina arises from association of the hydrocarbon chains of adsorbed ions, hemi-micelle formation should depend directly on chain length In a series of experiments involving alkylsulphonates with $8,10,12,14$, and 16 carbon atoms, Wakamatsu ${ }^{74}$ found that the three regions of the adsorption isotherms on alumina shifted to more dilute surfactant concentrations as the chain length increased. For $\mathrm{C} 8$ detergent, only region 1 exists, that is, hemi-micelles do not form with this short chain compound. By means of streaming potential experiments, an analogous phenomenon was observed for the behaviour of quartz in the presence of alkylammonium acetate. Figure 10 presents the zeta potential of quartz as measured by streaming potentials, as a function of the concentration of alkylammonium acetates with different hydrocarbon chain lengths ${ }^{78}$. This figure clearly indicates that as the number of carbon atoms in the chain is decreased, the bulk concentration of surfactant required for hemi-micelle formation increases. For chain lengths of eight carbon atoms, the amine salt behaves essentially identically to the ammonium salt.

By means of the Stern-Grahame model of the double layer, the contribution of the cohesive energy per mole of $\mathrm{CH}_{2}$ groups to the adsorption potential can be evaluated. If the standard free energy for removing one mole of $\mathrm{CH}_{2}$ groups from water through association is $\phi$, then the total contribution is $N \phi$ if $N$ is the number of $\mathrm{CH}_{2}$ groups in the chain. Thus, the contribution of this hydrophobic bond to the adsorption process is

$$
\Delta G_{\text {hydroph }}^{0}=N \phi
$$

The adsorption density, $\Gamma_{\delta}$ of surfactant ions in the Stern plane in the absence of chemisorption will be given by

$$
\Gamma_{\delta}=2 r C \exp \left(\frac{-\Delta \bar{G}_{\mathrm{ads}}^{0}}{R T}\right)=2 r C \exp \left(\frac{-z F \psi_{\delta}-N \phi}{R T}\right)
$$

where $r$ is the effective radius of the adsorbed ion and $C$ is the bulk concentration. Under conditions where $\zeta$ is zero, the Stern-Grahame expression for the specific adsorption of surfactant ions is

$$
\left(\Gamma_{\delta}\right)_{0}=2 r C_{0} \exp (-N \phi / R T)
$$

If $\left(\Gamma_{\delta}\right)_{0} / 2 r$ does not depend to any significant degree on chain length, a plot 


\section{INTERFACIAL PROCESSES IN MINERAL/WATER SYSTEMS}

of $N$ versus $C_{0}$, the concentration of surfactant required to bring $\zeta$ to zero should yield a straight line, the slope of which should permit evaluation of $\phi$. Figure 10 includes such a plot for alkylammonium ions on quartz ${ }^{78}$, and from this plot $\phi$ is calculated to be $1 R T$ (about $0.6 \mathrm{kcal}$ per mole of $\mathrm{CH}_{2}$ groups) in agreement with values obtained from solubility data and micelle formation.

\section{Physical versus chemical adsorption of organics at mineral/water interfaces}

At this point let us compare a system in which the surfactant adsorbs only through physical interaction with the surface with one in which covalent bonds are formed.

Perhaps the most widely studied system involving physical bond formation only is the adsorption of alkyl sulphonates on alumina. Infra-red spectroscopy shows no evidence of chemical bond formation between the sulphonate and the alumina surface. Furthermore, adsorption only occurs at $\mathrm{pH}$ values less than 9 , under which conditions the surface of the solid is positively charged ${ }^{69}$. Figure 11 illustrates how the electrophoretic mobility of alumina varies with $\mathrm{pH}$ in the presence of different amounts of sodium dodecyl sulphonate. At

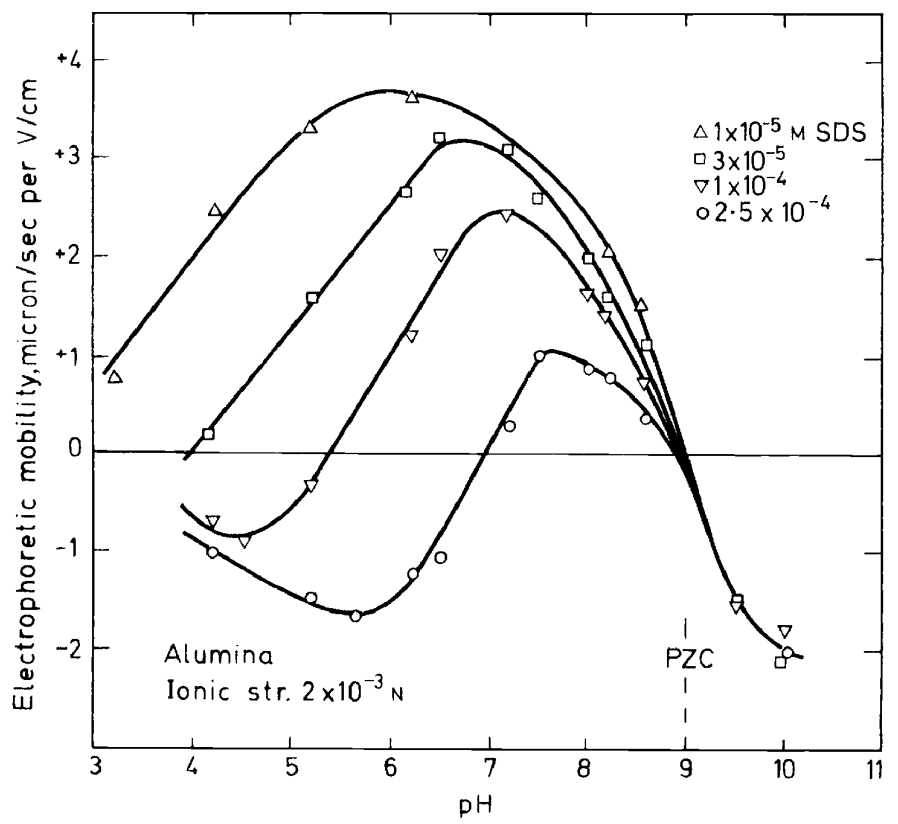

Figure 11. The effect of $\mathrm{pH}$ on the electrophoretic mobility of alumina in the presence of sodium dodecyl sulphonate.

pHs greater than 9, the curves coincide because sulphonate ions cease to adsorb under these conditions. (Joy, Watson and Cropton ${ }^{46}$ obtained analogous curves for haematite in the presence of cationic dodecylamine salts.) The sharp breaks that occur in the zeta potential curves as the $\mathrm{pH}$ is lowered merely reflect the formation of hemi-micelles at the interface. With higher 


\section{W. FUERSTENAU}

sulphonate concentrations, hemi-micelles form at less positively charged surfaces, i.e. at higher $\mathrm{pH}$ values. Specific adsorption and the reversal of zeta potential in this case is due to hemi-micelle formation. The decrease in zeta potential at very low pHs merely reflects double layer compression. Figure 12, which presents these same data in a different way with the zeta potential

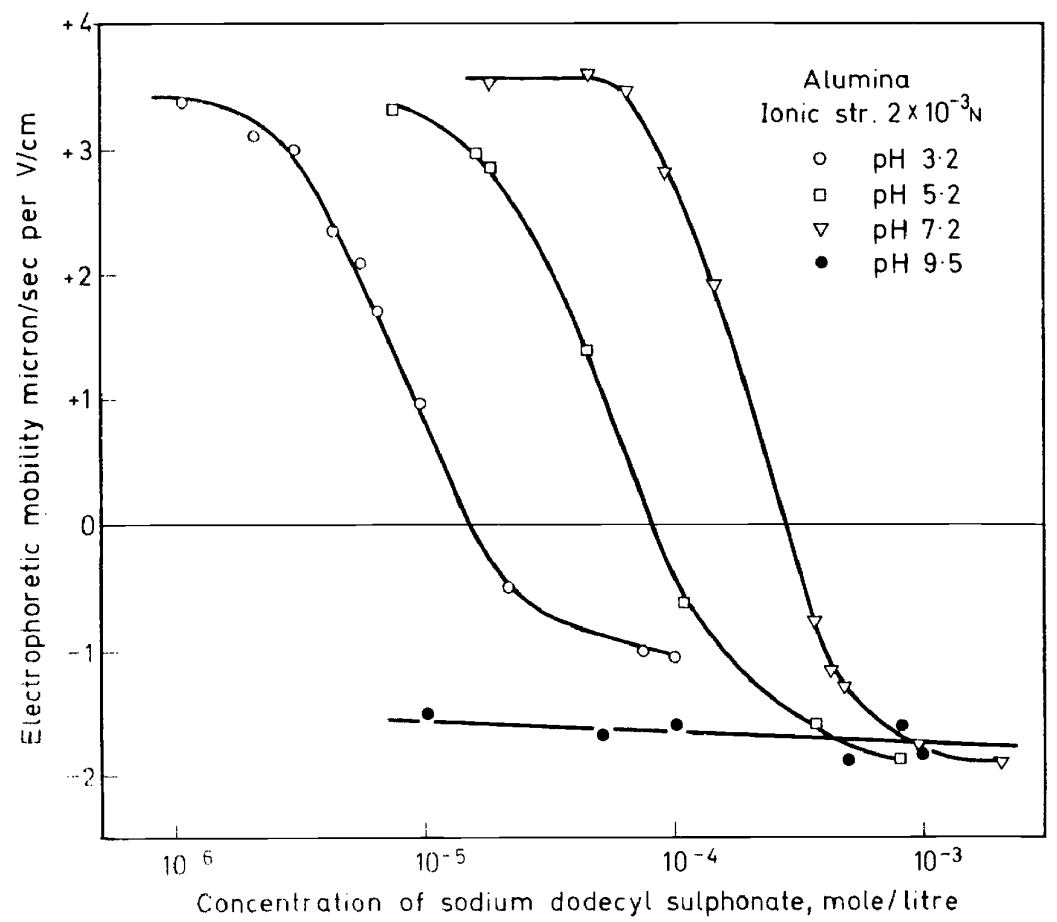

Figure 12. The effect of the concentration of sodium dodecyl sulphonate on the electrophoretic mobility of alumina at various $\mathrm{pH}$ values.

being plotted as a function of the concentration of sodium dodecyl sulphonate at different $\mathrm{pH}$ values, also illustrates the interrelation between specific adsorption and surface charge. At low pHs where the surface carries a high positive charge, the tendency of the sulphonate for specific adsorption increases markedly. On the other hand, when the $\mathrm{pH}$ exceeds the PZC, alkyl sulphonate ions lose their tendency for specific adsorption.

In a number of oxide mineral-surfactant systems, chemisorption occurs. Peck, Raby and Wadsworth ${ }^{72}$ recently demonstrated the chemisorption of oleate on haematite by means of infra-red spectroscopy; they showed that ferric oleate bonds are formed by the displacement of surface hydroxyls on haematite. As our example, let us consider the adsorption of oleate on rutile $\left(\mathrm{TiO}_{2}\right)$. Purcell and Sun ${ }^{59}$ carried out a detailed study of the flotation chemistry of this system and found the PZC of their rutile to occur at $\mathrm{pH} 6.7$. Figure 13 presents the zeta potential of rutile (evaluated by measurement of streaming potentials) as a function of $\mathrm{pH}$ for various additions of sodium 


\section{INTERFACIAL PROCESSES IN MINERAL/WATER SYSTEMS}

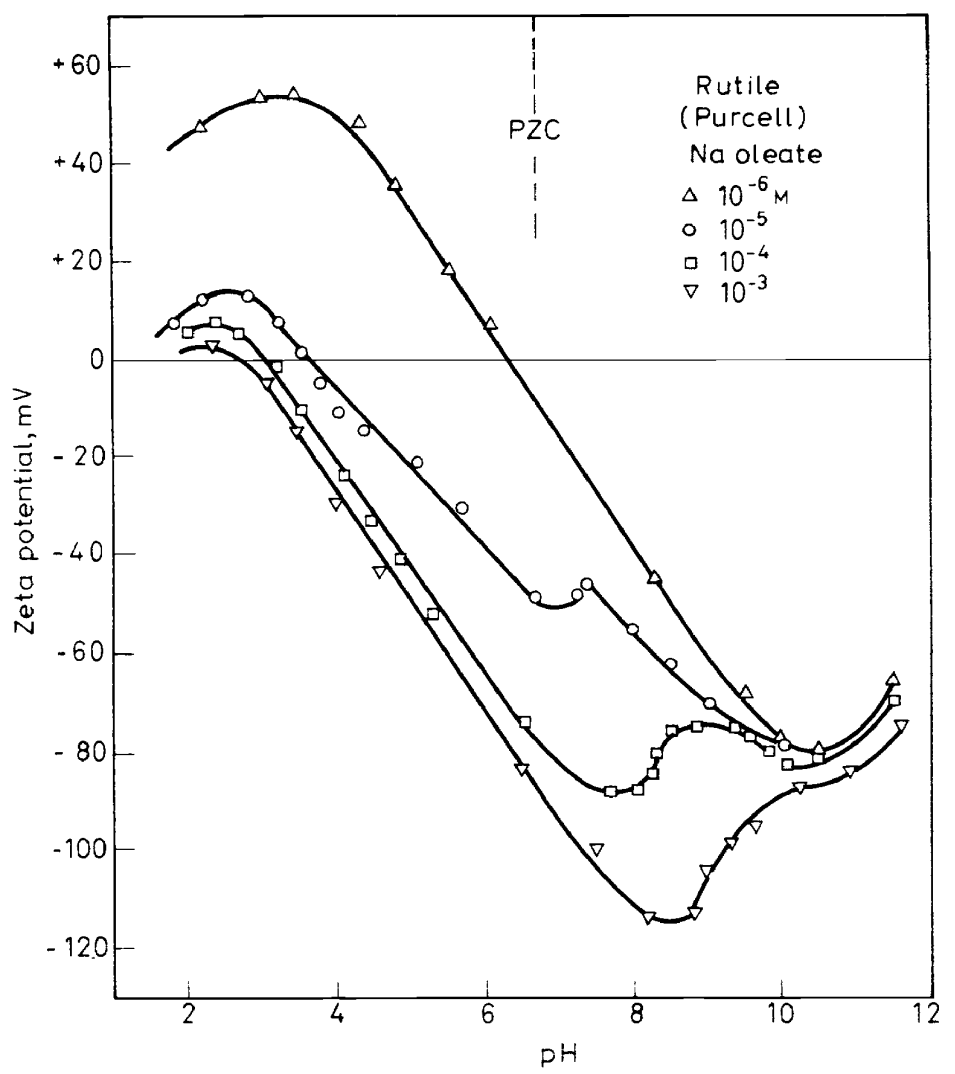

Figure 13. The effect of $\mathrm{pH}$ on the zeta potential of rutile in the presence of sodium oleate ${ }^{59}$.

oleate. In contrast to the alumina-sulphonate system (Figure 11), the PZC of rutile appears to have no influence on the adsorption behaviour of oleate. Only when the $\mathrm{pH}$ reaches a value of about ten does the zeta potential become essentially independent of oleate. Although a detailed analysis of these results has not been carried out, Figure 13 indicates that the electrical effects in the adsorption process are beginning to affect the chemical interaction at about $\mathrm{pH} 7$ with $10^{-5} \mathrm{M}$ oleate, at about $\mathrm{pH} 8$ with $10^{-4} \mathrm{M}$ oleate, and at about pH 9 in $10^{-3} \mathrm{M}$ oleate. In Figure 14, the same data are replotted showing the zeta potential of rutile as a function of the sodium oleate addition at various $\mathrm{pH}$ values. This figure clearly shows that only after the $\mathrm{pH}$ has attained a value of ten is the zeta potential independent of oleate (this is three $\mathrm{pH}$ units greater than the PZC), a behaviour in sharp contrast to that of the physically adsorbing sulphonate in Figure 12. By means of infra-red spectroscopy, it has been demonstrated that surface hydroxyls are displaced upon adsorption of oleate on rutile $\mathrm{e}^{89}$ and that an infra-red band indicating formation of a surface oleate results from the adsorption process. As already 




Figure 14. The effect of the addition of sodium oleate on the zeta potential of rutile at various pH values ${ }^{59}$.

stated, infra-red spectroscopy shows no such chemisorption in the aluminasulphonate system.

\section{APPLICATION OF ADSORPTION PHENOMENA TO FLOTATION}

By devising an apparatus in which flotation conditions can be accurately controlled, it has been possible to correlate flotation behaviour with adsorption phenomena. The modified Hallimond tube has been found to be exceedingly valuable for this purpose ${ }^{74}$.

In flotation systems in which the collector adsorbs only by physical interaction with the surface, flotation response with an anionic collector should be appreciable only below the PZC and with a cationic collector only above the PZC. Figure 15 illustrates the dependence of the flotation of alumina (corundum) on the PZC of the solid. In this figure, the location of the PZC is determined by evaluation of zeta potentials from streaming potential data in the absence of a supporting electrolyte ${ }^{56}$. With $4 \times 10^{-5} \mathrm{M}$ solutions of sodium dodecyl sulphonate and also dodecylammonium chloride, the flotation response is found to correlate well ${ }^{8,89}$ with the PZC. The intersection of the cationic and anionic flotation curves can even serve as a method for determining PZCs, provided only physical adsorption forces are active. Such flotation curves have been generated for a large number of minerals during the past decade, including the iron oxide minerals ${ }^{9,76}$, ilmenite ${ }^{81}$, the aluminosilicate minerals ${ }^{57}$, for example, and in each case the intersection of the two curves corresponds to the PZC of the minerals.

Figure 15 clearly illustrates that the surfactant in ionized form functions as the collector. Above $\mathrm{pH} 12$ when the cationic collector is primarily in the 
INTERFACIAL PROCESSES IN MINERAL/WATER SYSTEMS

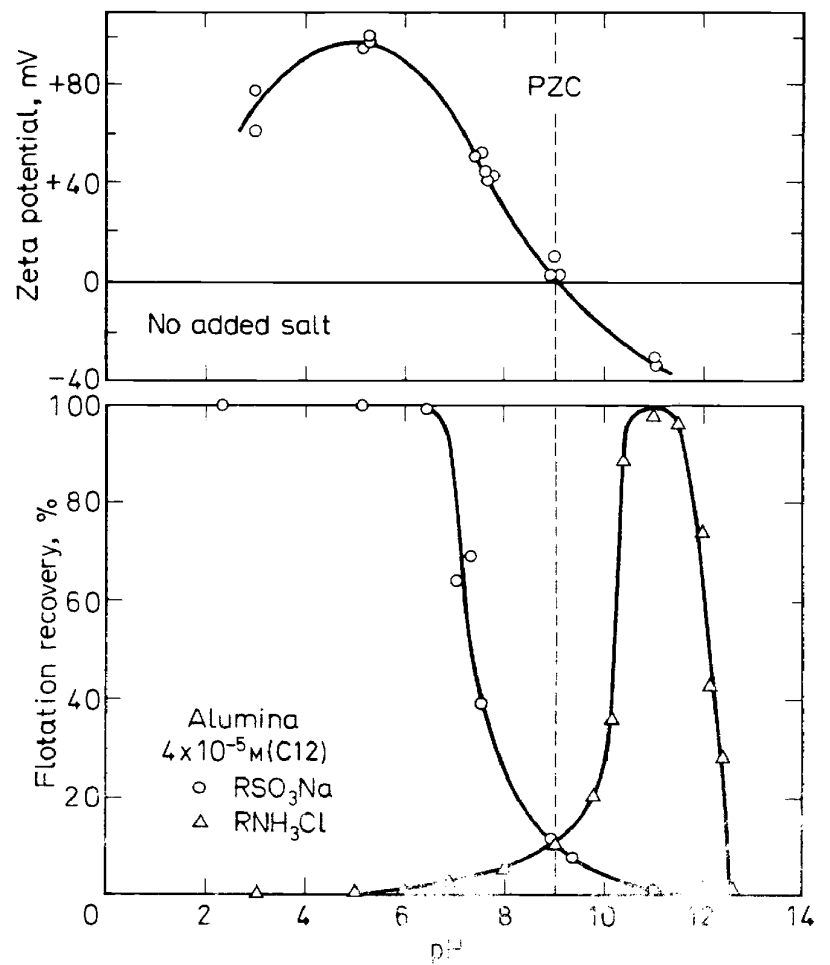

Figure 15. The effect of $\mathrm{pH}$ on the frotat on of alumina (coruncum) with $4 \times 10^{-5} \mathrm{M}$ sodium dodecyl sulphonate and with $4 \times 1\}^{-3} N_{*}$ dodecylammonium chloride; the effect of $;:$ in the zeta potential of alumina is also inclet

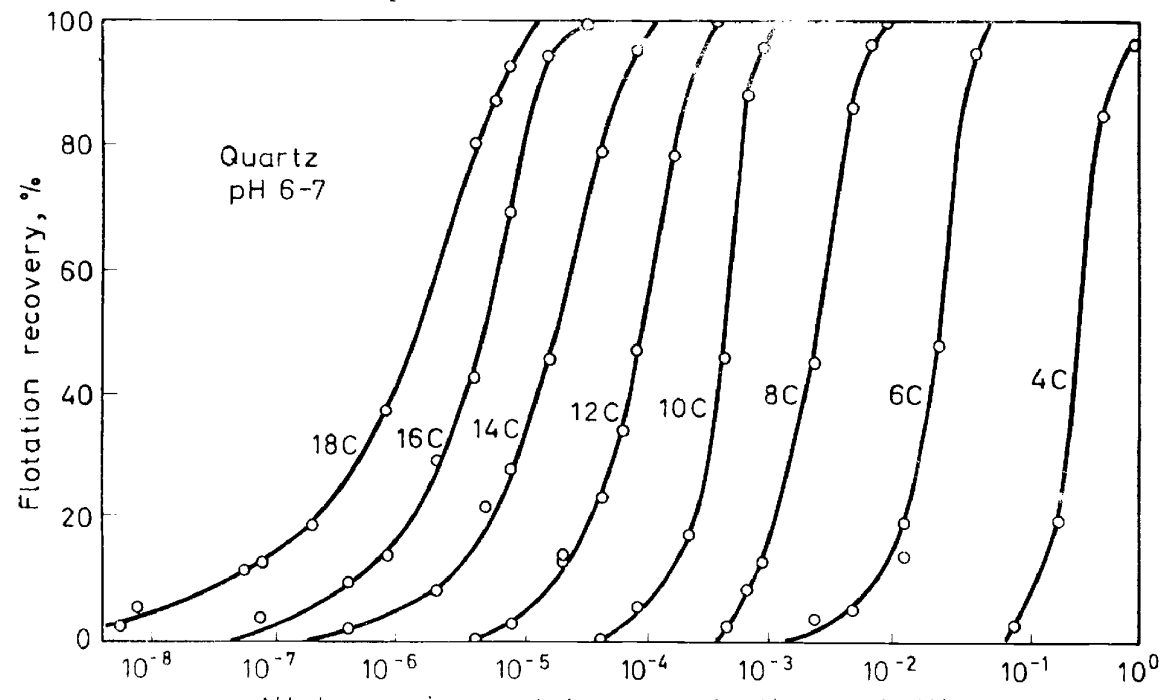

Alkylammonium acetate concentration, mole/litre

Figure 16. The effect of alkyl chain length on the relative flotation response of quartz in the presence of alkylammonium acetate collectors at neutral $\mathrm{pH}^{80}$. 


\section{W. FUERSTENAU}

hydrolysed molecular amine form, alumina ceases to respond to flotation. Similar effects have been demonstrated at low $\mathrm{pH}$ with sodium laurate as collector $^{8}$. Experiments of this kind clearly refute the postulate by Cook and Nixon $^{86,87}$, that the collector must be a neutral molecule.

Figure 9 shows that the contact angle is directly related to the amount of surfactant adsorbed at the solid/water interface; empirically in Regions I and II of the adsorption isotherm, cosine $\theta$ is approximately proportional to $\log \Gamma_{\mathrm{RSO}_{3}}$. Thus, some sort of direct relation might be expected between collector adsorption and flotation behaviour. Flotation response versus collector concentration curves indicate that rapid flotation occurs only when the adsorbed ions are anchored in the Stern plane (Figure 1). Consequently, any factor that affects the extent of adsorption in the Stern layers (hemimicelle formation) will have a very marked effect on flotation response. Since hemimicelle formation is related directly to the hydrocarbon chain length of adsorbed surfactant ions, flotation response must also be related to the hydrocarbon chain of the collector. Figure 16 presents the flotation recovery of quartz as a function of the concentration of different alkylammonium acetate collectors ${ }^{80}$ at neutral $\mathrm{pH}$. This figure shows a regular progression of the dependence of flotation recovery on concentration as the length of the hydrocarbon chain is increased. If the collector ion has four carbon atoms, rapid flotation occurs only when the collector concentration is about one molar; whereas with eighteen carbon atoms complete flotation is attained by about $10^{-5}$ molar. Analysis of these results in terms of the Stern-Grahame model yields a value of $1 R T$ for the contribution of one mole of $\mathrm{CH}_{2}$ groups to the specific adsorption potential ${ }^{80}$, in agreement with other hydrophobic bonding analyses.

\section{Chemisorption of the collector}

As has already been stated, if the collector adsorbs by physical forces only,

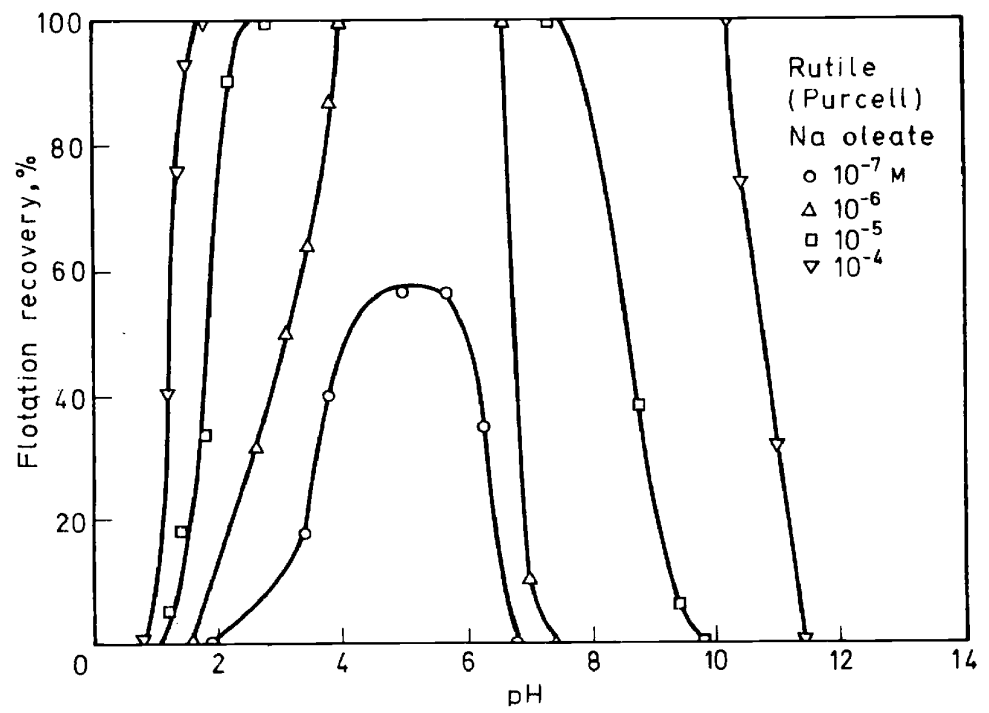

Figure 17. The effect of $\mathrm{pH}$ on the flotation of rutile with sodium oleate as collector ${ }^{59}$. 
the kind of results presented in Figure 15 are obtained; the PZC of the mineral controls flotation response. On the other hand, if the collector strongly chemisorbs on to the surface, then the PZC of the mineral will be of much less importance. Figure 17 presents the flotation response of rutile (PZC at $\mathrm{pH} 67$ ) in the presence of various amounts of sodium oleate as collector. At very low concentrations, $10^{-7}$ and $10^{-6}$ molar, rutile flotation does occur only below the PZC; but as the collector concentration is increased, the mineral responds to flotation at $\mathrm{pHs}$ considerably above the PZC. For example, with $10^{-4} \mathrm{M}$ oleate, rutile flotation can occur at $\mathrm{pHs}$ as high as about eleven; only at this high $\mathrm{pH}$ can the electrostatic repulsion completely counteract the tendency for chemisorption of the oleate. At low pHs flotation also ceases, but in this case, the collector has hydrolysed to the fatty acid which does not adsorb on the positively charged rutile surface.

\section{Flotation depression with inorganic ions}

Any ions that can compete with collector ions for sites in the double layer can inhibit the adsorption of collector and hence reduce flotation. In the flotation of positively charged alumina with anionic collectors, such ions might be $\mathrm{Cl}^{-}$and $\mathrm{SO}_{4}^{2-}$ competing with collector anions for the surface. In Figure 18 , the flotation recovery of alumina with sodium dodecyl sulphate as collector

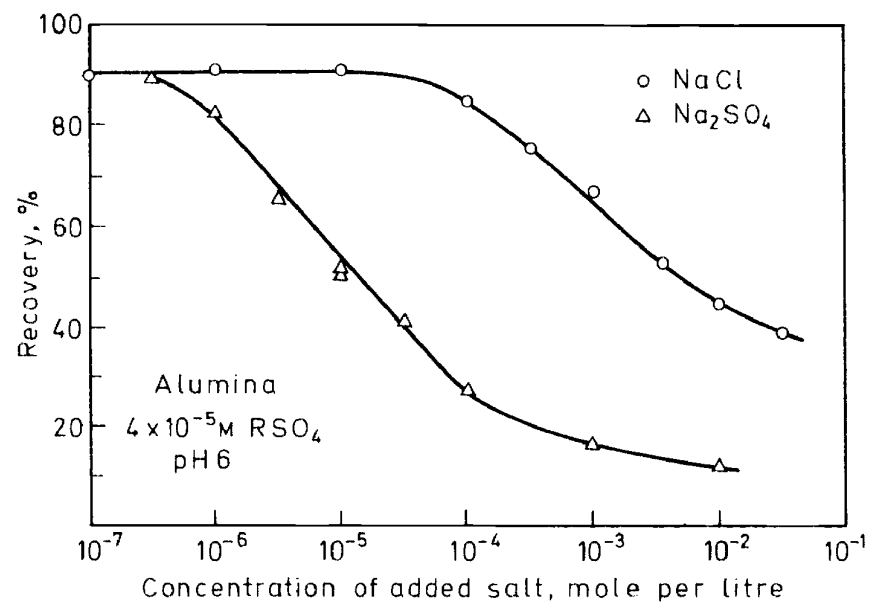

Figure 18. The depression of alumina flotation by sodium chloride and sodium sulphate with sodium dodecyl sulphate as the collector at $\mathrm{pH} 6^{8}$.

at $\mathbf{p H} 6$ is plotted as a function of the concentration of added sodium chloride and sodium sulphate ${ }^{8}$. This figure shows that both $\mathrm{Cl}^{-}$and $\mathrm{SO}_{4}^{2-}$ inhibit the flotation of positively charged alumina, but with the effect of $\mathrm{SO}_{4}^{2-}$ being about 500 times that of $\mathrm{Cl}^{-}$. The greater effect of $\mathrm{SO}_{4}^{2-}$ over that of $\mathrm{Cl}^{-}$in depressing alumina flotation results from the specific adsorption potential of $\mathrm{SO}_{4}^{2-}$ on alumina (Figure 6). Because of this, sulphate ions can displace the alkyl sulphate ions from the surface, thereby reducing flotation. Such phenomena become important in cationic flotation if sea water is used in the processing plant ${ }^{82}$. 


\section{Flotation activation with inorganic ions}

We have just seen the effects of sodium sulphate in inhibiting the flotation of positively charged alumina with anionic collectors. Figure 19 illustrates how the same inorganic salt can promote flotation. At $\mathrm{pH} 6$ alumina does not respond to flotation with dodecylammonium chloride as collector since the

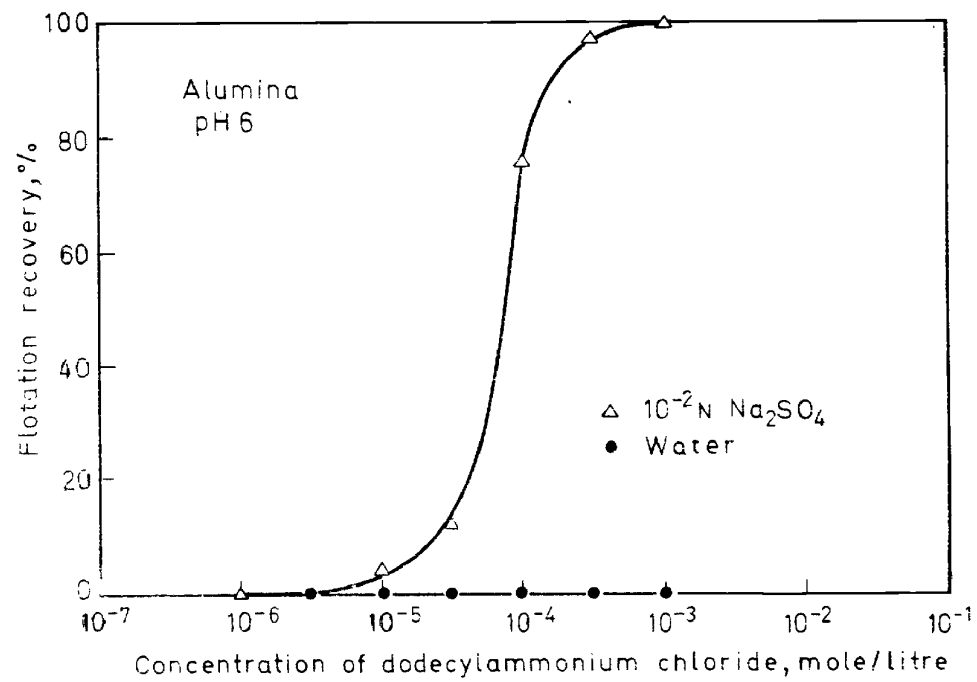

;ure 19. The activation of alumina with sodium sulphate for flotation with dodecylammonium acetate as collector at $\mathrm{pH} 6^{8}$.

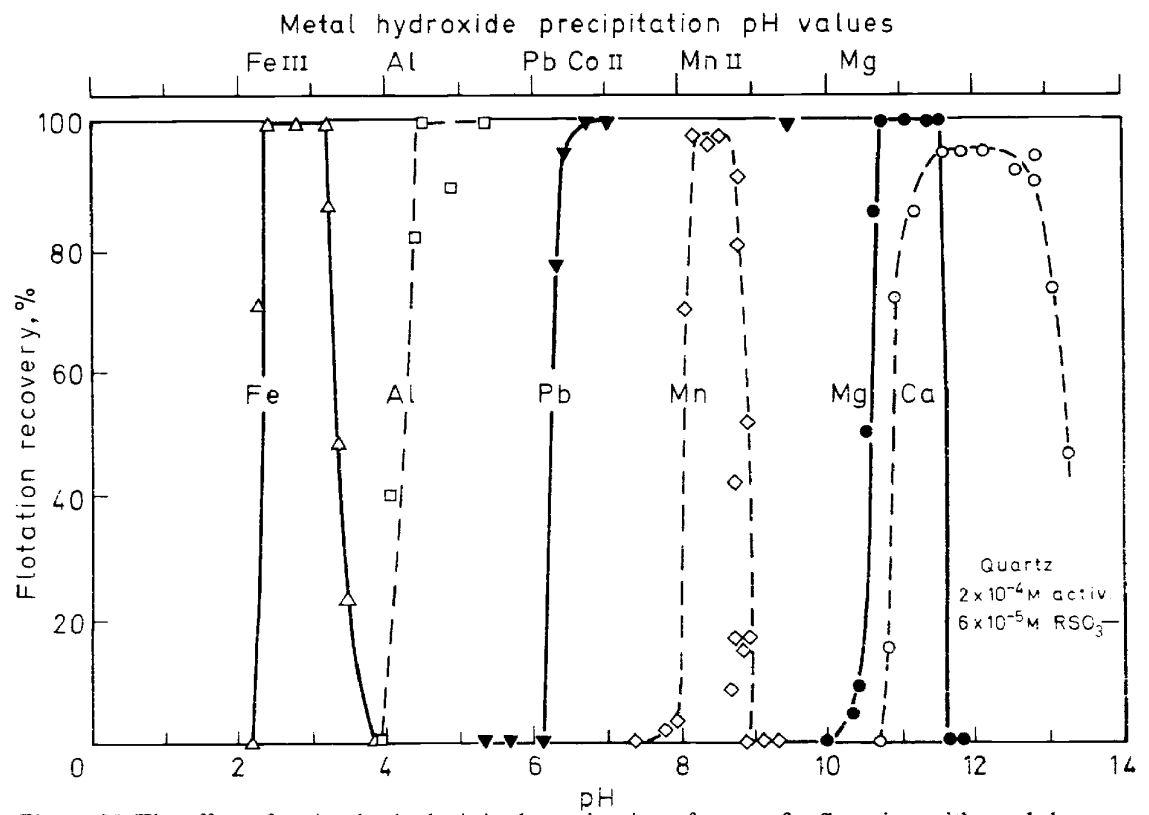

Figure 20. The effect of cation hydrolysis in the activation of quartz for flotation with a sulphonate as collector ${ }^{82}$. 
organic cations do not adsorb on the positively charged solid. On the other hand, by adding sufficient $\mathrm{SO}_{4}^{2-}$ ions to the system, the charge in the Stern plane is reversed and the solid can now adsorb the organic cations. In flotation terminology, sulphate ions are said to function as an activator; they serve as a link between the surface and the collector which are charged similarly in such systems.

In non-metallic mineral flotation, the most common examples of activation include the use of alkaline-earth cations to promote the flotation of oxides with soaps as the collector. In these processes, the role of cation hydrolysis has been exceedingly important. Although the significance of hydrolysis in the activation of minerals was pointed out over twenty years $\mathbf{a g o}^{83}$, only more recently has the concept been pursued with vigour in flotation research ${ }^{84}$. Figure 20 presents the flotation response of quartz ${ }^{84}$ as a function of $\mathrm{pH}$ in the presence of a number of activators (about $2 \times 10^{-4} \mathrm{M}$ activator) with a sodium alkylaryl sulphonate as collector (about $6 \times 10^{-5} \mathrm{M}$ collector). Under these conditions, the role of hydrolysis of the activator is clearly evident The activator begins to function effectively as the metal ion begins to hydrolyse and flotation ceases when the metal hydroxide begins to precipitate. In Figure 20, the decreasing side of the flotation recovery curves for aluminium ions and lead ions is omitted for reasons of clarity. Flotation ceases ${ }^{84}$ with aluminium activation at about $\mathrm{pH} 7$ and with lead activation at $\mathrm{pH} 12$. Lead activation ceases at high $\mathrm{pHs}$ because of the formation of the plumbite ion ${ }^{85}$.

Interpretation of the flotation behaviour of the complex silicate minerals may become complicated because these minerals may respond to flotation by a process of autoactivation; that is the silicate may partially dissolve with the cations hydrolysing and readsorbing as a flotation activator. In the limited work that has been done thus far, there is some indication that this kind of phenomenon may be occurring at the surface of many of the silicate minerals. In such systems, there may be a great difference between the behaviour of a thoroughly leached and washed mineral in the laboratory and a freshly ground mineral in the plant.

Finally, the suggestion has been made that chemisorption on oxides might depend on similar hydrolysis phenomena ${ }^{88}$. According to this postulate, surface metal ions may hydrolyse at some characteristic $\mathrm{pH}$, and under these conditions, for example, oleate is found to interact with the hydrolysed metal ions.

\section{SUMMARY}

Summarizing the status of present-day flotation technology, it can be said that the flotation separation of such ores as quartz-haematite mixture is relatively simple to achieve; but for many kinds of ores that are becoming increasingly significant, the problems of selective separation are becoming complex indeed. To enable us intelligently to find conditions for making such flotation separations, we must have a firm understanding of the physical chemistry of such processes. To achieve these objectives, detailed research must be carried out on fully characterized, pure mineral systems. For example, when we have found out how to characterize these minerals, perhaps the wide range of experimental values obtained for the PZCs of 


\section{W. FUERSTENAU}

oxide minerals can finally be explained and predicted. Other broad areas of research that need to be continued are outlined in the following paragraphs.

(1) Extensive research on the nature of the electrical double layer on oxide minerals is required before the charging process on oxides is unambiguously understood. Do oxides have double layers of constant capacitance, or is this merely an experimental artifact?

(2) Physical adsorption of collectors (detergents) at mineral/water interfaces has only been investigated for a few limited systems. Extensive work remains before we understand fully the nature of the configuration of the hydrocarbon chain in the adsorption process. Essentially nothing is known of how the structured water at the solid/liquid interface affects these adsorption processes.

(3) Research on chemisorption in flotation systems is relatively new and should be pursued with vigour. Chemisorption is important because it permits specific interaction between a given mineral and the collector, thereby providing a means for possibly achieving better selectivity. In physical adsorption situations, all minerals charged similarly respond similarly in flotation, with selectivity being reduced accordingly.

(4) At this stage we know little of the adsorption mechanism of multivalent ions on mineral surfaces. Adsorption of metallic cations should be investigated to determine what conditions control their adsorption and how this adsorption affects flotation. This is of importance not only because of desired activation but also because of the situation where undesired activation might occur.

(5) Colloid and surface phenomena are becoming even more important in the field of mineral processing because many ores remaining are very finegrained. How to recover colloidal-sized particles and the effect of colloidalsized particles on the recovery of coarser particles requires considerable research.

Finally, the principles involved with the application of solid/liquid interfacial phenomena to selective adsorption of flotation collectors can be extended to other fields such as those concerned with the geochemistry of mineral/water systems, soil science, inorganic ion exchangers etc. The results of research of the kind outlined above in all of these fields should be mutually beneficial to those concerned with selective adsorption phenomena.

\section{REFERENCES}

1 P. W. Richardson and H. E. Hawkes, Geochim. Cosmochim. Acta, 15, 6 (1958).

2 K. B. Krauskopf, Geochim. Cosmochim. Acta, 9, 1 (1956).

3 P. R. Hines, Froth Flotation, p 5. (D. W. Fuerstenau, Ed.) AIME: New York (1962).

${ }^{4}$ K. L. Sutherland and I. W. Wark, Principles of Flotation, Australian Institute of Mining and Metallurgy: Melbourne (1955).

5 A. M. Gaudin, Flotation, McGraw-Hill: New York (1957).

6 P. L deBruyn, Trans. AIME, 202, 299 (1955).

7 A. M. Gaudin and D. W. Fuerstenau, Trans. AIME, 202, 66, 958 (1955).

${ }^{8}$ H. J. Modi and D. W. Fuerstenau. Trans. AIME. 217. 381 (1960).

9 I. Iwasaki, S. R. B. Cooke and A. F. Colombo, U.S. Bur. Mines Rep. Invest. No. 5593 (1960).

10 M. J. Jaycock and R. H. Ottewill, Bull. Inst. Min. Metall. 72, 497 (1962-63).

${ }^{11}$ D. W. Fuerstenau, T. W. Healy and P. Somasundaran, Trans. AIME, 229, 34 (1964).

12 N. Tcheurekdjian, A. C. Zettlemoyer and J. J. Chessick, J. Phys. Chem 68, 773 (1964). 


\section{INTERFACIAL PROCESSES IN MINERAL/WATER SYSTEMS}

${ }^{13}$ D. F. Billet and R. H. Ottewill, Wetting, p 253, Society of Chemical Industry Monograph No. 25: London (1967).

14 F. M. Fowkes, Ind. Engng Chem. 56 (No. 12), 40 (1964).

15 C. A. Smolders, Rec. Trav. Chim Pays-Bas, 80, 651, 699 (1961).

16 L. A. Wood, J. Am. Chem. Soc. 68, 437 (1966).

${ }^{17}$ E. J. W. Verwey, Colloid Chem 7, 47 (1950).

18 J. A. Yopps and D. W. Fuerstenau, J. Colloid Sci. 19, 61 (1964).

19 T. W. Healy and D. W. Fuerstenau, J. Colloid Sci. 20, 376 (1965).

${ }^{20}$ G. A. Parks and P. L. deBruyn, J. Phys. Chem. 66, 967 (1962).

21 G. A. Parks, Advance Chem. Ser. 67, 121 (1967).

22 E. Matijevic, Principles and Applications of Water Chemistry, p 328. (S. D. Faust and J. V. Hunter, Eds.) Wiley: New York (1967).

23 D. C. Grahame, Chem. Rev. 41, 441 (1947).

24 O. Stern, Z. Elektrochem. 30, 508 (1924).

25 V. K. La Mer, in Principles and Applications of Water Chemistry, p. 241. (S. D. Faust and J. V. Hunter, Eds.) Wiley: New York (1967).

$26 \mathrm{~J}$. Th. G. Overbeek, in Colloid Science, Vol. I, Ch 4 and 5. (H. R. Kruyt) Elsevier: Amsterdam (1952).

27 D. Stigter, Preprint B/IV, 2. Proceedings of the Fourth International Congress on Surface Active Substances, Brussels (1964).

28 J. Lyklema and J. Th. G. Overbeek, J. Coloid Sci. 16, 501 (1961).

29 P. E. Bocquet, C. M. Sliepcevich and D. F. Bohr, Ind. Engng Chem. 48, 197 (1956).

${ }^{30}$ P. Somasundaran, T. W. Healy and D. W. Fuerstenau, J. Phys. Chem. 68, 3567 (1964).

31 H. J. Modi and D. W. Fuerstenau, J. Phys. Chem 61, 640 (1957).

32 S. M. Ahmed, Canad. J. Chem. 44, 1663 (1966).

33 R. A. Deju and R. Bhappu, Trans. AIME, 235, 88 (1966).

34 G. H. Bolt, J. Phys. Chem. 61, 1166 (1957).

35 Th. F. Tadros and J. Lyklema, J. Electroanal. Chem. 17, 267 (1968).

${ }^{36}$ H. C. Li and P. L. deBruyn, Surf. Sci. 5, 203 (1966).

${ }^{37}$ I Iwasaki, S. R. B. Cooke and H. S. Choi, Trans. AIME, 220, 394 (1961).

38 J. M. Cases, Ph.D. thesis, University of Nancy (1968).

39 D. J. O'Connor and A. S. Buchanan, Trans. Faraday Soc. 52, 397 (1956).

40 T. W. Healy, M.Sc. Thesis, University of Melbourne (1960).

${ }^{41}$ H. C. Parreira and J. H. Schulman, Advance Chem Ser. 33, 160 (1961).

42 R. J. Atkinson, A. M. Posner and J. P. Quirk, J. Phys. Chem. 71, 550 (1967).

43 S. A. Troelstra and H. R. Kruyt, Kolloidzschr. 101, 182 (1942).

44 S. M. Ahmed and D. Maksimov, Canad. J. Chem. 46,3841(1968).

45 G. W. Smith and T. Salman, Canad. Met. Quart, 5, 93 (1966).

46 A. S. Joy, D. Watson and R. W. G. Cropton, Trans. AIME, 229, 5 (1964).

47 I. Iwasaki, S. R. B. Cooke and H. S. Choi, Trans. AIME, 217, 237 (1960).

48 P. G. Johansen and A. S. Buchanan, Austral. J. Chem. 10, 398 (1957).

49 A. S. Joy and D. Watson, Proceedings of the Sixth International Mineral Processing Congress, Cannes, 1963, p 355. Pergamon: Oxford (1965).

50 G. A. Parks, Chem Rev. 65, 177 (1965).

51 T. W. Healy, A. P. Herring and D. W. Fuerstenau, J. Colloid Interface Sci. 21, 435 (1966).

52 J. Lyklema, J. Electroanal. Chem. 18, 341 (1968).

53 D. J. O'Connor, P. G. Johansen and A. S. Buchanan, Trans. Faraday Soc. 52, 229 (1956).

54 V. Pravdic and S. Sotman, Croat. Chem. Acta, 35, 247 (1963).

55 T. W, Healy and D. W. Fuerstenau, J. Colloid Interface Sci. 20, 376 (1965).

56 M. Robinson, M.S. Thesis, University of California, Berkeley (1962).

57 T. J. Smolik, Harman and D. W. Fuerstenau, Trans. AIME, 235, 367 (1966).

58 A. S. Joy, R. M. Manser, K. Lloyd and D. Watson, Trans. IMM, 75, C81 (1966).

59 G. Purcell and S. C. Sun, Trans. AIME, 226, 6, 13 (1963).

60 S. M. Ahmed and D. Maksimov, J. Colloid Interface Sci. 29, 97 (1969).

61 D. W. Fuerstenau and H. J. Modi, J. Electrochem. Soc. 106, 336 (1959).

${ }^{62}$ M. B. Abramson, M. J. Jaycock and R. H. Ottewill, J. Chem. Soc. 5034 (1964).

63 T. W. Healy, private communication.

${ }^{64}$ T. W. Healy, R. O. James and R. Cooper, Advanc. Chem. Ser. 79, 62 (1968). 


\section{W. FUERSTENAU}

${ }^{65}$ S. W. Clark and S. R. B. Cooke, Trans. AIME, 241, 334 (1968).

66 J. M. W. Mackenzie and R. T. O'Brien, Trans. AIME, 244, 168 (1969).

67 S. M. Ahmed and A. B. VanCleave, Canad. J. Chem. Engng, 43, 23 (February 1965).

68 P. L. deBruyn Trans. AIME, 202, 291 (1955).

${ }^{69}$ P. Somasundar. and D. W. Fuerstenau, J. Phys. Chem. 70, 90 (1966).

70 L. Ter-Minassian-Seraga, Advanc. Chem. Ser. 43, 232 (1964).

71 A. S. Peck and M. E. Wadsworth, U.S. Bur. Mines Rep. Invest. No. 6412 (1964).

72 A. S. Peck, L. H. Raby and M. E. Wadsworth, Trans. AIME, 235, 301 (1966).

73 A. M. Gaudin and D. W. Fuerstenau, Trans. AIME, 202, 958 (1955).

${ }^{74}$ T. Wakamatsu and D. W. Fuerstenau, Advanc. Chem. Ser. 79, 161 (1968).

75 T. Wakamatsu and D. W. Fuerstenau, to be published.

76 I. Iwasaki, S. R. B. Cooke and Y. S. Kim, Trans. AIME, 223, 113 (1962).

77 B. Tamamushi and K. Tamaki, Second International Congress of Surface Activity, Vol. III, 449 (1957).

${ }^{78}$ P. Somasundaran, T. W. Healy and D. W. Fuerstenau, J. Phys. Chem. 68, 3562 (1964).

79 D. W. Fuerstenau, P. H. Metzger and G. D. Seele, Eng. Min. J. 158, 93 (1957).

${ }^{80}$ D. W. Fuerstenau, T. W. Healy and P. Somasundaran, Trans. AIME, 229, 321 (1964).

81 H. S. Choi. Y. S. Kim and Y. H. Paik. Canad. Min. Met. Bull. (February 1967).

82 G. Y. Onoda and D. W. Fuerstenau, Seventh International Mining Processes Congress, 1964 : Proceedings, $\mathrm{p}$ 301. Gordon and Breach: New York (1965).

83 G. Gutzeit, Trans. AIME, 169, 276 (1946).

${ }^{84}$ M. C. Fuerstenau, C. C. Martin and R. B. Bhappu, Trans. AIME, 226, 449 (1963).

85 M. C. Fuerstenau, D. A. Rice, P. Somasundaran and D. W. Fuerstenau, Trans. I.M M. (London), 73, 381 (1965).

${ }^{86}$ M. A. Cook and J. C. Nixon, J. Phys. Colloid Chem. 54, 445 (1950).

${ }^{87}$ M. A. Cook, J. Colloid. Interface Sci. 28, 547 (1969).

88 M. C. Fuerstenau and D. A. Rice, Trans. AIME, 241, 453 (1968).

${ }^{89}$ Ralph W. M. Lai, unpublished results. 